Article

\title{
Three-Phase Short-Circuit Current Calculation of Power Systems with High Penetration of VSC-Based Renewable Energy
}

\author{
Niancheng Zhou, Jiafang $\mathrm{Wu}$ and Qianggang Wang * \\ State Key Laboratory of Power Transmission Equipment \& System Security and New Technology, \\ Chongqing University, Chongqing 400044, China; cee_nczhou@cqu.edu.cn (N.Z.); \\ 20161102036t@cqu.edu.cn (J.W.) \\ * Correspondence: yitagou@cqu.edu.cn; Tel.: +86-136-4055-8474
}

Received: 28 January 2018; Accepted: 23 February 2018; Published: 2 March 2018

\begin{abstract}
Short-circuit current level of power grid will be increased with high penetration of VSC-based renewable energy, and a strong coupling between transient fault process and control strategy will change the fault features. The full current expression of VSC-based renewable energy was obtained according to transient characteristics of short-circuit current. Furtherly, by analyzing the closed-loop transfer function model of controller and current source characteristics presented in steady state during a fault, equivalent circuits of VSC-based renewable energy of fault transient state and steady state were proposed, respectively. Then the correctness of the theory was verified by experimental tests. In addition, for power grid with VSC-based renewable energy, superposition theorem was used to calculate AC component and DC component of short-circuit current, respectively, then the peak value of short-circuit current was evaluated effectively. The calculated results could be used for grid planning and design, short-circuit current management as well as adjustment of relay protection. Based on comparing calculation and simulation results of 6-node $500 \mathrm{kV}$ Huainan power grid and 35-node $220 \mathrm{kV}$ Huaisu power grid, the effectiveness of the proposed method was verified.
\end{abstract}

Keywords: high penetration; VSC-based renewable energy; short-circuit current; DC component; peak value of short-circuit current

\section{Introduction}

Grid-connected power generation scale of renewable energy sources, like wind energy and solar energy, is continuously expanding, and renewable energy sources connected to grid with high penetration will become an important trend of future electric power system [1-4]. With higher penetration of renewable energy power generation in electric power system, short-circuit currents injected by them during short-circuit fault will increase current at fault point, and consequently, electrical equipment are faced with higher requirements for dynamic and thermal stability [5]. In the meantime, the strong coupling between diversity of their fault transient states and control strategy will change grid fault features and its distribution $[6,7]$. Therefore, short-circuit current calculation of power grid with a high penetration of renewable energy sources are basic for the electric power system planning and design, equipment selection, and protection configuration.

Renewable energy source generation is divided into electric rotating machinery and voltage source converter based renewable energy (VSC-based renewable energy), where the former includes synchronous generators and induction generators; the latter includes photovoltaic power generation, direct-driven wind power, energy storage, etc. For electric rotating machinery, short-circuit calculation of synchronous generator is very mature, model of voltage source and series impedance is the basis of fault analysis [8]. Induction generators have different short-circuit current characteristics when 
compared with synchronous generators [9], when short-circuit faults occur, they are unable to maintain their terminal voltage without an external excitation current. Many methods are used to study the short-circuit current of induction generators, including real-time simulation tools [10], dynamic simulation software [11,12] and physical experiments [13]. However, the peak value of short-circuit current for electric rotating machinery is very high, while that is limited for VSC-based renewable energy due to its control strategy of converter. It can be divided into voltage-control and current-control converter according to difference in controlled inner loops [14]. Current control mode can realize grid-connecting synchronization and over-current limitation easily; so current control is usually used in grid-connected VSC-based renewable energy [14,15]. Short-circuit current, provided by VSC-based renewable energy, is determined by converter control and limited by thermal limiting current of power switch, so it has fault features different from conventional power source [16].

In aspect of transient equivalent model of VSC-based renewable energy, it is helpful in evaluating the short-circuit current by establishing a short-circuit calculation model considering fault current characteristic. It was analyzed in [17] that fault transient characteristics and influencing factors of VSC-based renewable energy, and the fault responses of VSC-based renewable energy are very different from that of conventional sources. Literature [18] presents a model for calculating transient current of VSC-based renewable energy. However, the influence of the control strategy and controller parameters of VSC-based renewable energy is not considered. Then calculation models of steady short-circuit current was established, when considering the control strategy of VSC-based renewable energy [19]. In [20], based on the analysis of two control strategies, a fault sequence component model of VSC-based renewable energy was proposed. Furtherly, in consideration of fault ride-through, a new improved model of VSC-based renewable energy was analyzed in [21]. However, the models mentioned above were only specific to steady short-circuit current of VSC-based renewable energy under different faults, transient AC component and decaying DC component of short-circuit current were not discussed.

In aspect of short-circuit current calculation, based on the method of equivalent generator voltage at the fault location, an algorithm principle is proposed to calculate short-circuit current in distribution networks, but control and current-limiting features of VSC-based renewable energy were not considered in [22]. Therefore, when considering the current-limiting characteristics of VSC-based renewable energy, a short-circuit current algorithm of VSC-based renewable energy, connected to radiation-type power distribution network, was proposed in [23]. Meanwhile, VSC-based renewable energy can be treated as PQ and $I \theta$ buses, so the power flow and short-circuit current can be calculated in the same way by a proposed method in [24]. According to [25], VSC-based renewable energy was represented as a constant PQ source or a constant current source in corresponding to the changes of terminal voltage, and Gauss-Seidel method was used to calculate short-circuit current. While a universal algorithm considering the AC component of short-circuit current was proposed further, based on Newton-Raphson iterative technique [26]. But, none of the methods mentioned above gave a processing mode for high penetration of VSC-based renewable energy during short-circuit current calculation, and the calculation method of peak value was not mentioned.

Anhui power grid is a part of east China power grid, which supplies power to 16 cities in Anhui province. The Anhui power grid is connected to the power grids in other provinces through two $1000 \mathrm{kV}$ and seven $500 \mathrm{kV}$ lines. The internal regions in Anhui power grid are interconnected by the backbone network with $500 \mathrm{kV}$ and $220 \mathrm{kV}$ lines. By September 2017, the total installed power capacity of Anhui power grid is $38.13 \mathrm{GW}$, including the thermal power $32.71 \mathrm{GW}$, the photovoltaic power $2.77 \mathrm{GW}$, the wind power $2.1 \mathrm{GW}$, and the hydropower $0.55 \mathrm{GW}$. Anhui power grid mainly includes Huaisu power grid (including Huaibei and Suzhou power grids), Bozhou power grid, Huainan power grid and so on, which is shown in Figure 1. The renewable energy sources have been developed rapidly, and Figure 1 also shows the operation and planning photovoltaic power stations in Anhui power grid. It is noted that the most photovoltaic power stations are connected into Huaisu and Huainan power grids. The photovoltaic power capacities of Huaisu and Huainan power grids are $1410 \mathrm{MW}$ and $1440 \mathrm{MW}$ in Table 1. It can be seen from Table 1, the proportions of renewable power 
capacity relative to total installed capacity are $31.8 \%$ in Huaisu power grid and $37 \%$ in Huainan power grid. The photovoltaic power is a type of VSC-based renewable energy, thus the Huaisu and Huainan power grids are with high penetration of VSC-based renewable energy.

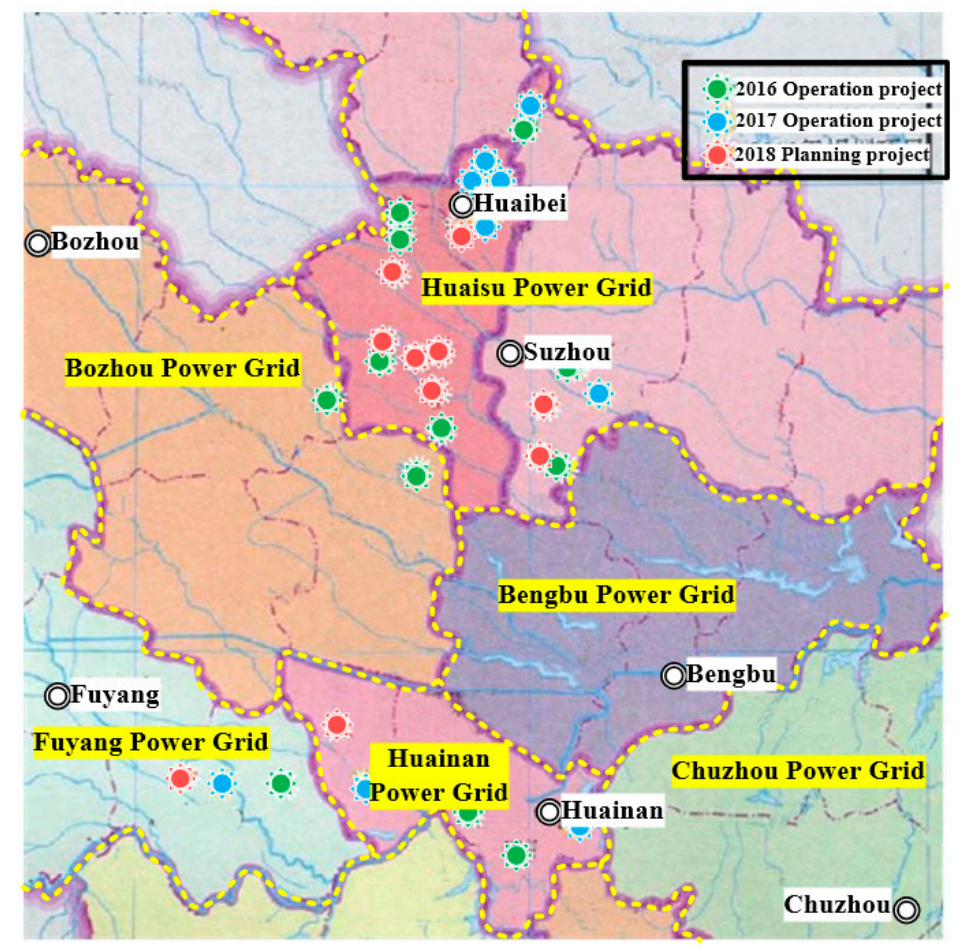

Figure 1. Operation and planning photovoltaic power stations in Anhui power grid.

Table 1. Installed power capacities of Huaisu and Huainan power grids.

\begin{tabular}{cccc}
\hline Region & Thermal Power & Photovoltaic Power & Wind Power \\
\hline Huaisu & $3720 \mathrm{MW}$ & $1410 \mathrm{MW}$ & $326 \mathrm{MW}$ \\
Huainan & $2512 \mathrm{MW}$ & $1440 \mathrm{MW}$ & $38 \mathrm{MW}$ \\
\hline
\end{tabular}

In order to determine the short-circuit current level of power grid with high penetration of VSC-based renewable energy, in this paper, from the perspective of short-circuit current features of VSC-based renewable energy, a full current expression of three-phase short-circuit current was obtained. Meanwhile, according to the output current characteristics presented by VSC-based renewable energy in different period of faults, the equivalent circuits of fault transient state and steady state were proposed respectively. Then, the above contents are verified by experimental test and related calculation results. Besides, superposition theorem was used to decompose fault network into normal component network and fault component network, AC component and DC component of short-circuit current in power grid can be calculated, while the peak value can be obtained further. Finally through simulation results of Anhui power grid in MATLAB/Simulink (R2017a, MathWorks, Natick, MA, USA), the proposed calculation method was verified.

\section{Three-Phase Short-Circuit Current of VSC-Based Renewable Energy}

\subsection{Three-Phase Short-Circuit Current and Transient Equivalent Circuit of VSC-Based Renewable Energy}

Unlike conventional sources, short-circuit current of VSC-based renewable energy is influenced by their control strategies. However, transition from normal state to short-circuit steady state, the change of short-circuit current still exists a transient state, including decaying AC periodic component 
and decaying DC component. Similar to the three-phase short-circuit current of synchronous generator in $[8,27]$, when short-circuit steady state is taken into account, a-phase short-circuit current expression of a VSC-based renewable energy under three-phase short-circuit fault can be written as:

$$
i_{\mathrm{a}}(t)=\left[\left(I_{\mathrm{m}}^{\prime}-I_{\mathrm{m} \infty}\right) e^{-\frac{t}{T^{\prime}}}+I_{\mathrm{m} \infty}\right] \cos \left(\omega t+\theta_{0}\right)+\left(I_{\mathrm{m}|0|} \cos \delta_{0}-I_{\mathrm{m}}^{\prime} \cos \theta_{0}\right) e^{-\frac{t}{T_{\mathrm{a}}}}
$$

where $I_{\mathrm{m}}^{\prime}$ is initial amplitude of AC component, which gradually attenuates according to time constant $T^{\prime}$, and finally attenuates to steady value $I_{\mathrm{m} \infty}, \omega=2 \pi f, f$ is grid frequency, $I_{\mathrm{m}|0|}$ is current amplitude before short-circuit, $\left(I_{\mathrm{m}|0|} \cos \delta_{0}-I_{\mathrm{m}}^{\prime} \cos \theta_{0}\right)$ is initial value of DC component, $T_{\mathrm{a}}$ is attenuation time constant of DC component, $\delta_{0}$ is initial phase angle of the current before short-circuit, and $\theta_{0}$ is phase angle of steady short-circuit current. As AC components are symmetrical, $\left( \pm 120^{\circ}+\delta_{0}\right)$ and $\left( \pm 120^{\circ}+\theta_{0}\right)$ are used to replace $\delta_{0}$ and $\theta_{0}$ in the above expression, b-phase and c-phase current expressions of VSC-based renewable energy under three-phase short-circuit fault can also be obtained.

According to Equation (1), the short-circuit process of VSC-based renewable energy consists of transient state and steady state, as we all know, in the steady state, the VSC-based renewable energy is equivalent to a current source, and will output stable short-circuit current according to command current. However, it is not suitable for transient state, equivalent circuit of the VSC-based renewable energy will no longer be a current source, which is related to internal control of the inverter.

Next, a further analysis of transient equivalent circuit is carried out. Schematic diagram of a grid-connected VSC-based renewable energy is shown in Figure 2a, where the DC side is a photovoltaic array simulator, and the maximum power point tracking (MPPT) control is adopted to achieve the maximize output power under different light intensity and ambient temperature. By a photovoltaic inverter with $L C$ filter, the VSC-based renewable energy converts DC to AC, and is then connected to the power grid through a step-up transformer. Its terminal voltage $u$ and current $i$, are collected by measuring elements and is fed into the controller, so that the controller can adjust the output current of inverter effectively. $L_{\mathrm{f}}$ and $C_{\mathrm{f}}$ are filter inductor and capacitor, respectively, and $Z_{1}$ is line impedance from the grid-connected point of photovoltaic to the fault point.

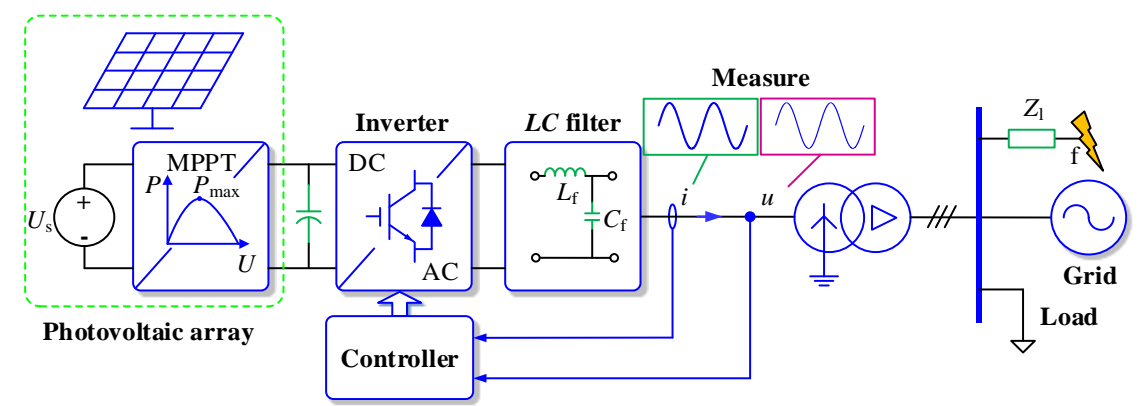

(a)

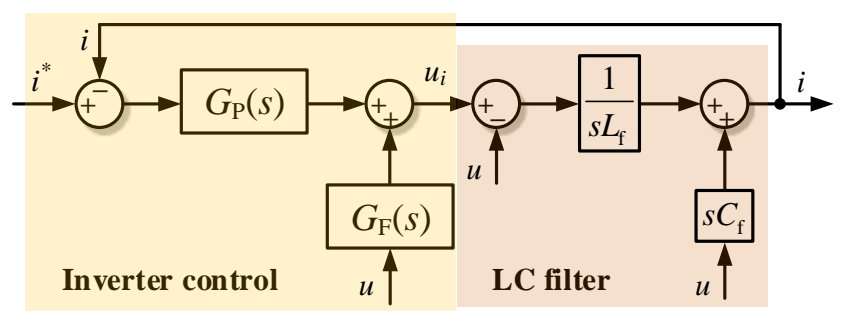

(b)

Figure 2. A grid-connected VSC-based renewable energy: (a) schematic diagram; (b) control block diagram.

A simplified control block diagram of inverter and $L C$ filter is shown in Figure $2 b$. In this figure, $u_{\mathrm{i}}$ and $u$ represent output voltage of inverter and terminal voltage in Figure $2 \mathrm{a}, i^{*}$ represents command 
current, $G_{\mathrm{P}}(s)$ and $G_{\mathrm{F}}(s)$ are the transfer function of PI controller and feedforward control, respectively, according to the control diagram of Figure $2 b$, the following expressions can be obtained [28]:

$$
\left\{\begin{array}{l}
{\left[i^{*}(s)-i(s)\right] \cdot G_{\mathrm{P}}(s)+u(s) \cdot G_{\mathrm{F}}(s)=u_{\mathrm{i}}(s)} \\
{\left[u_{\mathrm{i}}(s)-u(s)\right] \cdot \frac{1}{s L_{\mathrm{f}}}+u(s) \cdot s C_{\mathrm{f}}=i(s)}
\end{array}\right.
$$

By simplifying two equations in Equation (2) and eliminating $u_{\mathrm{i}}(s)$, the relationship between terminal voltage $u$, current $i$ and command current $i^{*}$ is obtained as:

$$
\frac{G_{\mathrm{P}}(s)}{1-s^{2} C_{\mathrm{f}} L_{\mathrm{f}}-G_{\mathrm{F}}(s)} \cdot i^{*}(s)=\frac{s L_{\mathrm{f}}+G_{\mathrm{P}}(s)}{1-s^{2} C_{\mathrm{f}} L_{\mathrm{f}}-G_{\mathrm{F}}(s)} \cdot i(s)+u(s)
$$

According to closed loop transfer function models of inverter, controller, and filter in Equation (3), the transfer function of output voltage and command current and equivalent output impedance can be obtained [28-30], then equivalent of VSC-based renewable energy can be realized through Thevenin or Norton circuit. For VSC-based renewable energy ports, the equation $\dot{E}_{\mathrm{s}}=Z \cdot \dot{I}+\dot{U}$ is established, where $\dot{E}_{\mathrm{s}}$ is equivalent potential, which is equal to the product of transfer function $G(s)$ with command current $i^{*}$, and $G(s)$ is related to control strategy; $\dot{U}$ and $\dot{I}$ are terminal voltage and current respectively; $\mathrm{Z}$ is virtual control impedance, determined by control parameters.

In reality, to enhance control performance of VSC-based renewable energy, internal and external virtual impedances will be added to the controller [28], where internal virtual impedance is used for resonance damping of filter [29]; external virtual impedance is used to regulate output impedance of VSC-based renewable energy, including external series impedance, is used to realize its power decoupling control in low-voltage power grid [30,31], while external parallel impedance is used to harmonic current distribution between multiple sources [32]. VSC-based renewable energy for fault ride-through operation is still under controllable operation status after short-circuit, combining controller's virtual impedance and LC filter, equivalent circuit of VSC-based renewable energy is shown in Figure 3a.

In Figure 3a, equivalent internal potential $\dot{E}_{\mathrm{s}}$ is equal to product of transfer function $G(s)$ and command current, and $G(s)$ is transfer function related to control strategy. $Z_{\mathrm{vc}}$ and $Z_{\mathrm{vg}}$ are virtual damping impedances inhibiting filter resonance, $Z_{\mathrm{vp}}$ and $Z_{\mathrm{vs}}$ are parallel and series virtual impedances to improve output characteristics of VSC-based renewable energy; $x_{L}$ and $x_{C}$ are equivalent reactance of inductance and capacitance of $L C$ filter, respectively; $Z_{\mathrm{tl}}$ represents equivalent impedance of transformer and line; $Z_{\mathrm{L}}$ and $Z_{1}$ are load impedance and network-side line impedance respectively; and, $\dot{E}_{\text {grid }}$ and $Z_{\mathrm{s}}$ are grid voltage and its short-circuit impedance. It can be known from Equation (1) that short-circuit process of a VSC-based renewable energy contains transient state and steady state. In transient state, initial AC component of VSC-based renewable energy is jointly decided by internal potential, equivalent impedance, and fault condition; while, in steady state, VSC-based renewable energy will output stable short-circuit current according to command current.

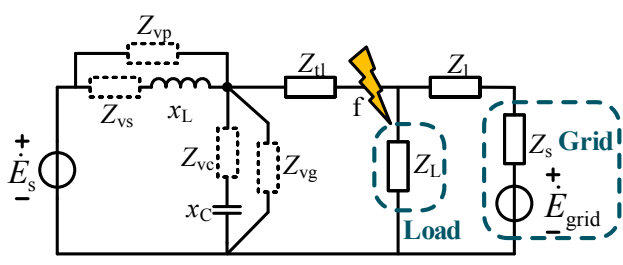

(a)

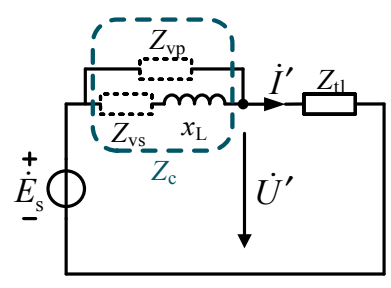

(b)

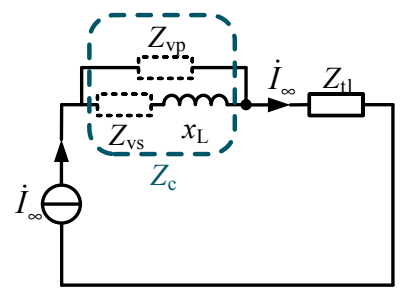

(c)

Figure 3. Transient equivalent circuits of a VSC-based renewable energy: (a) the whole circuit of three-phase short-circuit fault; (b) the circuit of fault transient period; (c) the circuit of fault steady period. 
Based on Figure 3a, equivalent circuits of fault transient and steady period can be obtained as shown in Figure 3b,c. Earth loop (post-fault voltage is low and earth loop current has minor influence) is neglected in short-circuit current calculation, then VSC-based renewable energy in transient period is equivalent to series between a voltage source and impedance; VSC-based renewable energy in steady period presents a current source and outputs stable short-circuit current. In Figure $3 b, \dot{U}^{\prime}$ is the terminal voltage of VSC-based renewable energy; $\dot{I}^{\prime}$ and $\dot{I}_{\infty}$ are transient current and steady current respectively, which are output by VSC-based renewable energy. According to Figure 3b, KVL theorem is used to solve the equivalent circuit to obtain the internal potential of VSC-based renewable energy during transient period as:

$$
\dot{E}_{\mathrm{s}}=\dot{U}^{\prime}+\frac{Z_{\mathrm{vp}}\left(Z_{\mathrm{vs}}+\mathrm{j} x_{\mathrm{L}}\right)}{Z_{\mathrm{vp}}+\left(Z_{\mathrm{vs}}+\mathrm{j} x_{\mathrm{L}}\right)} \cdot \dot{I}^{\prime}=\dot{U}^{\prime}+Z_{\mathrm{c}} \cdot \dot{I}^{\prime}
$$

where $Z_{\mathrm{vp}}, Z_{\mathrm{vs}}$ and $x_{\mathrm{L}}$ are combined into equivalent impedance $Z_{\mathrm{c}}$, which is expressed by virtual frame in Figure $3 \mathrm{~b}$. It is assumed that potential $\dot{E}_{\mathrm{s}}$ maintains unchanged during short-circuit moment, terminal voltage falls and transient current $\dot{I}^{\prime}$ appears, and this transient current will not exceed the limiting current output by VSC-based renewable energy. After the peak value of short-circuit current appears, it gradually attenuates to steady value $\left|\dot{I}_{\infty}\right|$ under the effect of controller. AC component and DC component will attenuate, respectively, according to different time constants, where attenuation time constant $T^{\prime}$ of periodic AC component is related to transfer function $G(s)$; DC component attenuation time constant $T_{\mathrm{a}}$ [27] is jointly decided by equivalent impedance $Z_{c}$, transformer and line impedance $Z_{\mathrm{t} 1}$, as follow:

$$
T_{\mathrm{a}}=\frac{L_{\mathrm{c}}+L_{\mathrm{tl}}}{R_{\mathrm{c}}+R_{\mathrm{tl}}}
$$

where $L_{\mathrm{c}}$ and $L_{\mathrm{tl}}$ are inductances of equivalent impedance $Z_{\mathrm{c}}$ and $Z_{\mathrm{tl}}$ respectively, $R_{\mathrm{c}}$ and $R_{\mathrm{tl}}$ are their resistances, respectively.

In reality, it is very difficult to obtain the value of equivalent impedance $Z_{c}$, and its impedance parameter can be estimated in way of experimental test. In this paper, DC component attenuation time constant of VSC-based renewable energy was used to estimate equivalent impedance parameter. Considering that unknown parameters were equivalent resistance and inductance of VSC-based renewable energy, in this experiment, transformer inductance $L_{\mathrm{tl}}$ and resistance $R_{\mathrm{tl}}$ were changed to obtain DC attenuation time parameters under two external conditions (mean time constants were taken after 20 times of test under each situation) respectively as $T_{\mathrm{a} 1}$ and $T_{\mathrm{a} 2}$, and equation set containing two unknown parameters $-L_{\mathrm{c}}$ and $R_{\mathrm{c}}$-was established:

$$
\left\{\begin{array}{l}
T_{\mathrm{a} 1}=\frac{L_{\mathrm{c}}+L_{\mathrm{tt} 1}}{R_{\mathrm{c}}+R_{\mathrm{t} 11}} \\
T_{\mathrm{a} 2}=\frac{L_{\mathrm{c}}+L_{\mathrm{t} 12}}{R_{\mathrm{c}}+R_{\mathrm{t} 12}}
\end{array}\right.
$$

where $T_{\mathrm{a} 1}$ and $T_{\mathrm{a} 2}$ are attenuation time constants obtained under two test conditions, $L_{\mathrm{t} 11}$ and $L_{\mathrm{t} 12}$ are corresponding test inductances, $R_{\mathrm{t} 11}$ and $R_{\mathrm{t} 12}$ are their resistances. Then inductance $L_{\mathrm{c}}$ and resistance $R_{\mathrm{c}}$ of equivalent impedance $Z_{\mathrm{c}}$ are

$$
\left\{\begin{array}{l}
L_{\mathrm{C}}=\frac{T_{\mathrm{a} 2} L_{\mathrm{t} 11}-T_{\mathrm{a} 1} L_{\mathrm{t} 12}+T_{\mathrm{a} 1} T_{\mathrm{a} 2}\left(R_{\mathrm{t} 12}-R_{\mathrm{t} 11}\right)}{T_{\mathrm{a} 1}-T_{\mathrm{a} 2}} \\
R_{\mathrm{C}}=\frac{T_{\mathrm{a} 2} L_{\mathrm{t} 11} / T_{\mathrm{a} 1}-L_{\mathrm{t} 2}+T_{\mathrm{a} 2}\left(R_{\mathrm{t} 12}-R_{\mathrm{t} 11}\right)}{T_{\mathrm{a} 1}-T_{\mathrm{a} 2}}+\frac{L_{\mathrm{t} 11}}{T_{\mathrm{a} 1}}-R_{\mathrm{t} 11}
\end{array}\right.
$$

Thus impedance parameter of Thevenin equivalent circuit in Figure 3 can be estimated, short-circuit current of VSC-based renewable energy after fault should be smaller than the limiting current, and only in this way can VSC-based renewable energy remain fault ride-through operation. Due to limitations of modulation factors and DC voltage during pulse width modulation, its internal 
potential $\left|\dot{E}_{\mathrm{s}}\right|$ can only be regulated within permissible range, namely $E_{\mathrm{smin}} \leq\left|\dot{E}_{\mathrm{s}}\right| \leq E_{\mathrm{smax}}$. Limiting current value of VSC-based renewable energy is set as $I_{\max }$, then terminal voltage conditions corresponding to fault ride-through operation of VSC-based renewable energy are as follows:

$$
\left|\dot{E}_{\mathrm{s}}-\dot{U^{\prime}}\right| \leq I_{\max }\left|Z_{\mathrm{c}}\right|
$$

Phase difference of internal potential $\dot{E}_{\mathrm{s}}$ ahead of terminal voltage $\dot{U}^{\prime}$ is set as $\delta$, then permissible fluctuation range of terminal voltage $\left|\dot{U}^{\prime}\right|$ can be obtained according to Equation (8):

$$
\left|\dot{U}^{\prime}\right| \geq\left|\dot{E}_{\mathrm{s}}\right| \cos \delta-\sqrt{\left(I_{\max }\left|Z_{\mathrm{c}}\right|\right)^{2}-\left(\left|\dot{E}_{\mathrm{s}}\right| \sin \delta\right)^{2}}
$$

\subsection{Experimental Test of Three-Phase Short-Circuit Current of a VSC-Based Renewable Energy}

The experimental platform, as established through schematic diagram of Figure 2a, is shown in Figure 4, where programmable DC power source Chroma $62050 \mathrm{H}-600 \mathrm{~S}$ with detailed specifications in [33] is used as photovoltaic array simulator, photovoltaic inverter ES-5TLT (Huaiwei (V-way), Guangdong, China) is a $5 \mathrm{~kW}$ three-phase inverter, and programmable AC power source Chroma 61845 with detailed specifications in [34] and AC electronic load are used to simulate fault voltage and grid load. During three-phase short-circuit fault, both convert-type source and power grid will inject short-circuit current towards fault point $\mathrm{f}$. When electrical distance between VSC-based renewable energy and fault point is too short, terminal voltage will decrease greatly and corresponding short-circuit current will exceed upper limit of converter output current, at the moment, photovoltaic inverter will experience automatic blocking and quit operation [14,21], without any short-circuit current being injected into power grid.

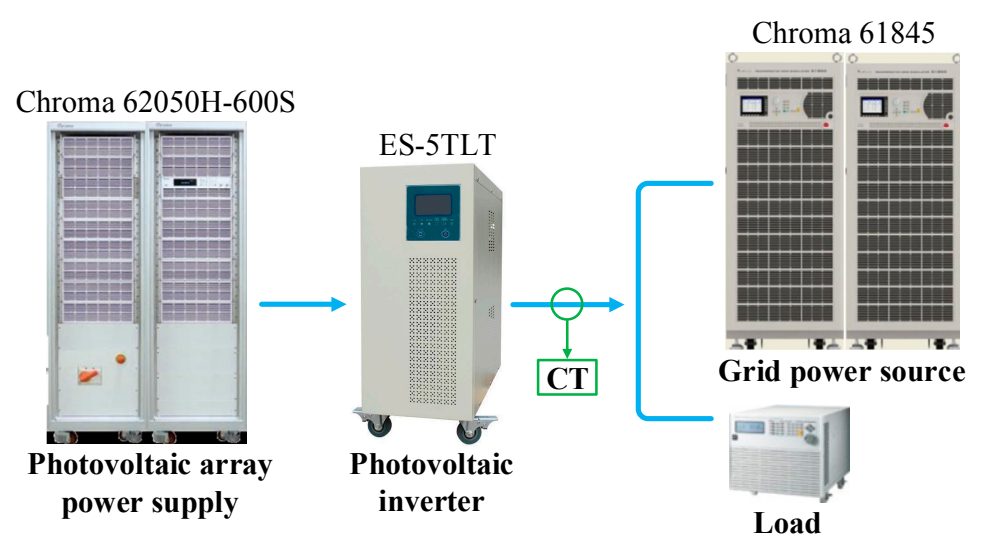

Figure 4. An experimental platform of a $5 \mathrm{~kW}$ VSC-based renewable energy.

Different fault conditions are simulated by regulating fall amplitude of output voltage of programmable power source, and photovoltaic inverter is under normal operation, active power is set as $0.5 \mathrm{pu}$, and reactive power is 0 , three-phase short-circuit happens at $t=0.1 \mathrm{~s}$ and the fault lasts 10 periods. The test is conducted under three post-fault voltages $U^{\prime}(0.2 \mathrm{pu}, 0.18 \mathrm{pu}$ and $0.17 \mathrm{pu})$, and the obtained three-phase short-circuit current waveforms of a VSC-based renewable energy are shown in Figure 5. It is found by gradually reducing post-fault voltage amplitude with 0.01 pu being the interval that when post-fault voltage is $0.18 \mathrm{pu}$, this photovoltaic inverter can still continuously injected short-circuit current. After voltage continuously drops to $0.17 \mathrm{pu}$, it experiences automatic blocking when output current is nearby maximum value, and afterwards, its current gradually decreases to 0 .

Both Figure $5 \mathrm{a}, \mathrm{b}$ show the situations where short-circuit current of a VSC-based renewable energy doesn't exceed limiting current, as drop amplitude of terminal voltage continues to increase, 
short-circuit current of the inverter will gradually rise, and when its command current reaches upper limit, current-limiting link of controller will be started to reduce actual output current of the inverter [14]. DC component attenuation (expressed by dotted line in the middle) of a VSC-based renewable energy, obtained by halving the vertical line between two envelop lines (dotted lines), is shown in Figure 5a,b. As inductive current in short-circuit loop cannot experience sudden change, this will generate DC component to make instantaneous value of post-fault short-circuit current be equal to the value before fault happens.

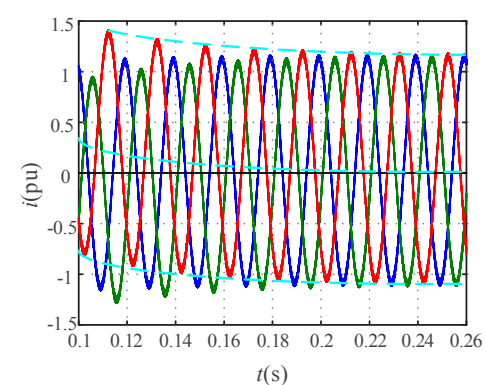

(a)

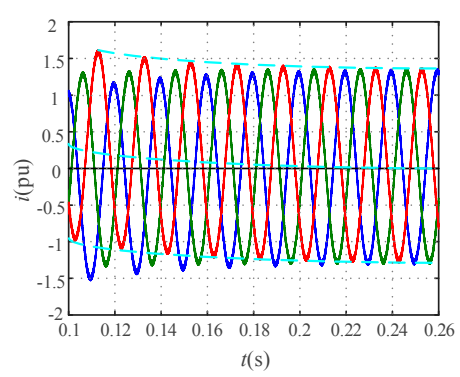

(b)

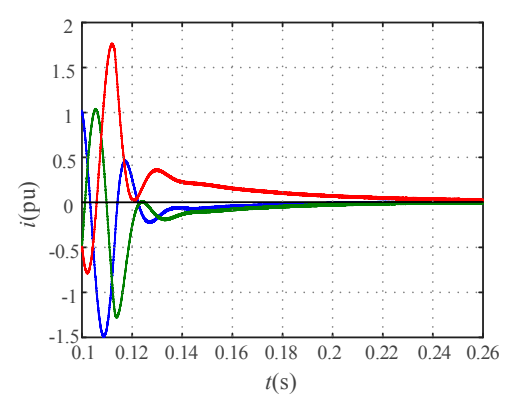

(c)

Figure 5. Measured three-phase short-circuit currents of a VSC-based renewable energy. (a) $U^{\prime}=0.2$ $\mathrm{pu}$; (b) $U^{\prime}=0.18 \mathrm{pu}$; (c) $U^{\prime}=0.17 \mathrm{pu}$.

DC components of three-phase short-circuit current in Figure 5a are extracted separately, and decomposed three-phase DC components are shown in Figure 6a. It can be known that three-phase DC components are unequal, but all of them attenuate according to the same exponential rule and finally attenuate to zero. In the meantime, the AC components of short-circuit current can be further decomposed, as shown in Figure 6b. AC components are mainly three-phase sinusoidal current with equal amplitude and symmetrical phase positions, and envelop lines of AC components present attenuation trend, for the convenience of observation, only a-phase current is presented in Figure $6 \mathrm{~b}$. According to exponential attenuation rule analysis of envelop lines of AC components, AC components of VSC-based renewable energy only attenuate according to one time constant, which is different from attenuation process of two time constants (sub-transient and transient) of synchronous generator. Thus the correctness of full current Equation (1) proposed in Section 2.1 is further verified.

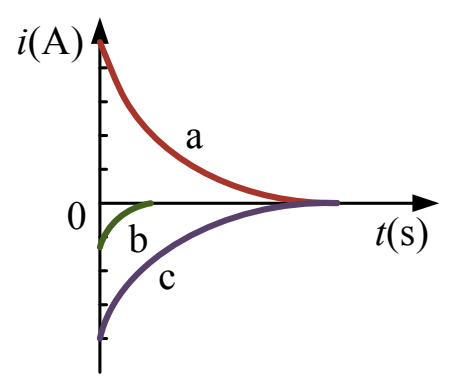

(a)

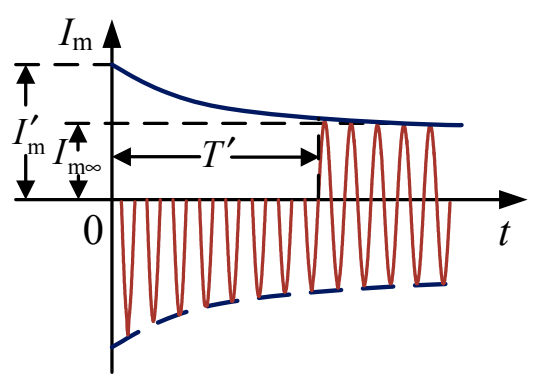

(b)

Figure 6. Decomposing of short-circuit current waveforms: (a) DC component; (b) AC component.

Through multiple tests of photovoltaic inverter ES-5TLT, inductance $L_{\mathrm{c}}$ and resistance $R_{\mathrm{c}}$, calculated by Equation (7), are $0.149 \mathrm{pu}$ and $0.069 \mathrm{pu}$ respectively, namely $\left|Z_{\mathrm{c}}\right|=0.164 \mathrm{pu}$. Terminal voltage of photovoltaic inverter, in Figure $5 b$, falls to 0.18 pu after fault, initial AC component value of its three-phase short-circuit current is $1.346 \mathrm{pu}$, which is smaller than limiting current $I_{\max }=1.4 \mathrm{pu}$, and thus, equivalent internal potential of VSC-based renewable energy can be estimated as $0.401 \mathrm{pu}$. 
Equivalent potential $\left|\dot{E}_{\mathrm{s}}\right|$, impedance $\left|Z_{\mathrm{c}}\right|$ and limiting current $I_{\max }$ are substituted into Equation (9), operation range of post-fault terminal voltage under different phase differences is calculated, as shown in Figure 7, where blue lines show post-fault terminal voltages corresponding to Figure $5 b, c$, and shadow area is permissible range of fault voltage.

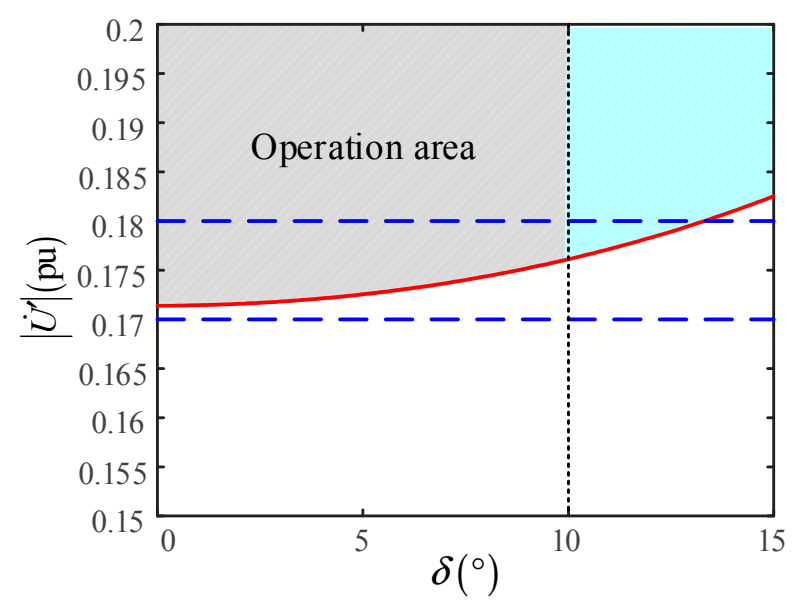

Figure 7. Operation range of terminal voltage of a VSC-based renewable energy during faults.

Phase difference between internal potential and terminal voltage is generally smaller than $10^{\circ}$, when the terminal voltage falls to $0.18 \mathrm{pu}$, blue line is located in operation range of terminal voltage, and VSC-based renewable energy maintains fault ride-through operation. However, when terminal voltage fails to $0.17 \mathrm{pu}$, the fault voltage is outside shadow area and it is lower than critical voltage, which results in inverter blocking, as shown in Figure 5c, and output current of VSC-based renewable energy gradually reduces to 0 .

According to requirements for grid connection test of photovoltaic inverter, when its fault voltage is higher than $0.2 \mathrm{pu}$, fault ride-through operation must be kept within a certain time. When it's lower than $0.2 \mathrm{pu}$, there are differences in fault ride-through operation abilities of different products. During the experimental process, test data with small voltage drop amplitude are used to obtain equivalent impedance and internal potential, and then critical voltage of VSC-based renewable energy under fault ride-through operation is estimated, and it can be used to determine setting of voltage drop amplitude in the experiment. Equivalent circuits of VSC-based renewable energy under transient and steady states are applied to short-circuit current calculation of traditional power grid, and then short-circuit currents under different short-circuit period can be calculated.

\section{Three-Phase Short-Circuit Current Calculation of Power Systems with High Penetration of VSC-Based Renewable Energy}

\subsection{AC Component Calculation of Three-Phase Short-Circuit Current in Power Systems}

For short-circuit current calculation in power systems, the system equivalent circuit is usually simplified as a linear electric network with active components [35] in Figure 8. The superposition theorem can be applied to calculate voltage and current responses in this active network. Using the superposition theorem, when a fault is occurred at node $f$ through the impedance $z_{f}$, then the fault node is considered to be supplied with a negative voltage source, equal to the voltage at that location in normal state, while all of the other sources are set to zero. 


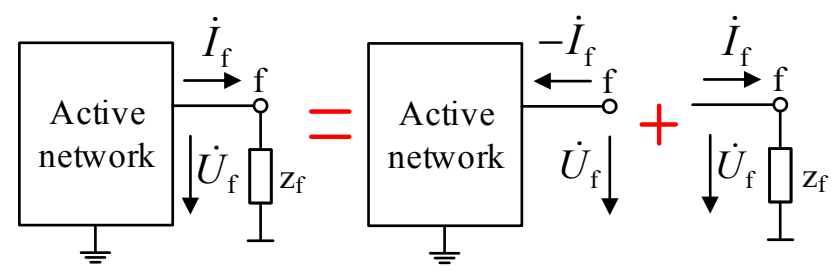

Figure 8. Equivalent network for symmetrical short-circuit analysis.

In the figure, $\dot{I}_{\mathrm{f}}$ and $\dot{U}_{\mathrm{f}}$ represent the short-circuit current and voltage at the fault node, and the original part of the fault branch can be separated. Compared with the normal network, a short-circuit fault is equivalent to adding an injection current $-\dot{I}_{\mathrm{f}}$ to the fault node. Therefore, the nodal voltage $\dot{U}_{\mathrm{i}}$ in the network $[8,35]$ can be expressed as:

$$
\dot{U}_{\mathrm{i}}=\sum_{\mathrm{j} \in \mathrm{G}} Z_{\mathrm{ij}} \dot{I}_{\mathrm{j}}-Z_{\mathrm{if}} \dot{I}_{\mathrm{f}}
$$

where $G$ represents the set of active nodes in the network, $\dot{I}_{\mathrm{j}}$ is the injected current at active nodes, $Z_{\mathrm{ij}}, Z_{\mathrm{if}}$ are the impedance elements of nodal impedance matrix of the network. It can be seen that the nodal voltage is superposed by two parts. The first part is the voltage generated by all of the power in the network when $\dot{I}_{\mathrm{f}}=0$, namely normal component; the second part is the voltage generated by short-circuit current $\dot{I}_{\mathrm{f}}$, namely fault component. Thus, the post-fault voltage $\dot{U}_{\mathrm{i}}$ can be calculated by superposing the above two components, and the corresponding current can also be obtained by the same superposition idea.

After a short-circuit fault occurs in the power system with VSC-based renewable energy, a certain increasing amplitude will occur to VSC-based renewable energy as relative to output current under normal operation [36]. At the moment, an increment of current injected by VSC-based renewable energy will generate additional fault component in short-circuit current. It is assumed that VSC-based renewable energy is installed at node $k$, and the short-circuit current at node $k$ can be decomposed into normal component and fault component by the superposition theorem. Then, the AC fault component of short-circuit current can be obtained according to Equation (1):

$$
\begin{aligned}
\Delta i_{\mathrm{k}}(t) & =i_{\mathrm{k}}(t)-i_{\mathrm{k}|0|}(t)=\left[I_{\mathrm{m} \infty} \cos \left(\omega t+\theta_{0}\right)-I_{\mathrm{m}|0|} \cos \left(\omega t+\delta_{0}\right)\right]+\left(I_{\mathrm{m}}^{\prime}-I_{\mathrm{m} \infty}\right) e^{-\frac{t}{T^{\prime}}} \cos \left(\omega t+\theta_{0}\right) \\
& =\Delta i_{\mathrm{k} \infty}(t)+\Delta i_{\mathrm{k}}^{\prime}(t)
\end{aligned}
$$

where $i_{\mathrm{k}}(t)$ is the short-circuit current injected by VSC, $i_{\mathrm{k}|0|}(t)$ and $\Delta i_{\mathrm{k}}(t)$ are the normal component and the fault component, $\Delta i_{\mathrm{k} \infty}(t)$ and $\Delta i_{\mathrm{k}}^{\prime}(t)$ are the fault steady component and the fault transient component respectively. AC component amplitude of short-circuit current presents attenuation trend with time. But in engineering calculation, more attention is given to initial value and steady value of its AC component, so two moments in transient period $t=0$ and steady period $t=\infty$, during fault process, are selected to calculate initial value and steady value of AC component.

Figure 9 shows equivalent circuit of AC fault component, fault transient component $\Delta \dot{I}_{\mathrm{k}}^{\prime}$ is injected by VSC-based renewable energy to the node in transient period of short-circuit. According to Figure $3 b$, VSC-based renewable energy is equivalent to series connection between voltage source $\Delta \dot{E}_{\mathrm{k}}$ and equivalent impedance $Z_{\mathrm{ck}}$. For the convenience of analysis, Norton theorem is used to make voltage source equivalent to current source, as shown in Figure $9 \mathrm{a}$, where $\Delta \dot{I}_{\mathrm{k}}^{\prime}=\Delta \dot{E}_{\mathrm{k}} / Z_{\mathrm{ck}}$. In steady period of power grid fault, it can be known from Figure $3 c$ that VSC-based renewable energy is equivalent to current source injecting fault steady component $\Delta \dot{I}_{\mathrm{k} \infty}$ at the node, and its equivalent circuit is shown in Figure 9b. 


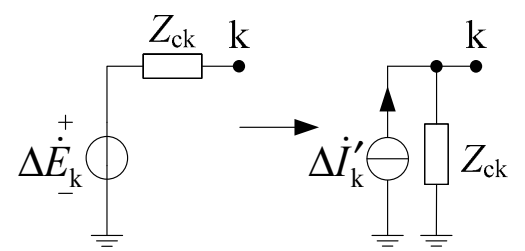

(a)

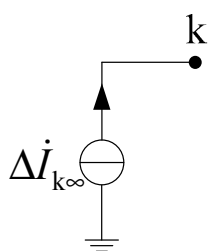

(b)

Figure 9. Equivalent circuit of AC fault-component of a VSC-based renewable energy: (a) transient period; (b) steady period.

When considering power grid with high penetration of VSC-based renewable energy, it is assumed that $\mathrm{m}$ sets VSC-based renewable energy are installed in power grid, and three-phase short-circuit fault happens at node $\mathrm{f}$. Superposition theorem is used to decompose fault network into normal component network and fault component network as shown in Figure 10, where $G$ represents power source node and $G_{1} \sim G_{k}$ are grid-connected points of conventional power sources; $G_{k+1} \sim G_{k+m}$ are grid-connected points of VSC-based renewable energy; $D$ represents load node, $D_{1} \sim D_{n}$ are load grid-connected points, constant impedance $Z$ represents load and $f$ is short-circuit fault point (for a bolted short-circuit, $z_{\mathrm{f}}=0$ ).

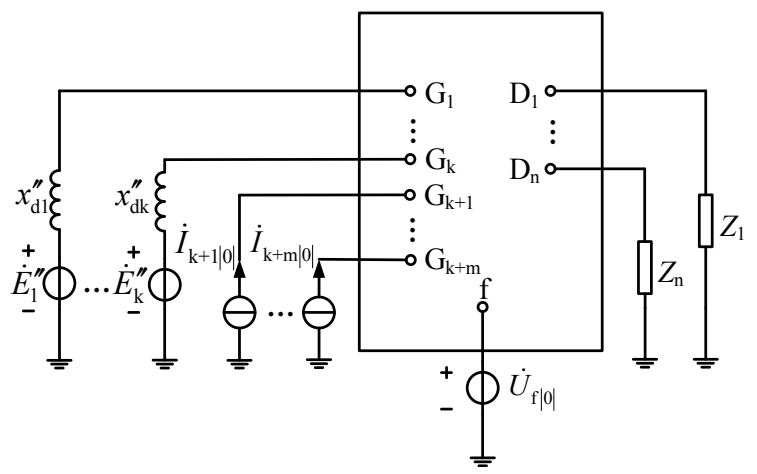

(a)

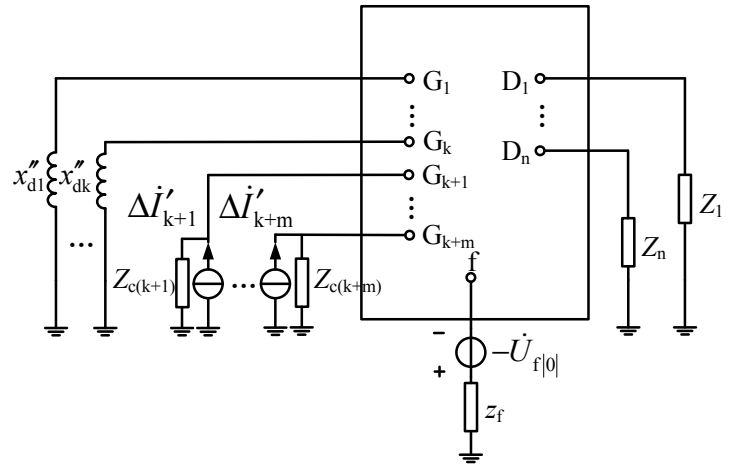

(b)

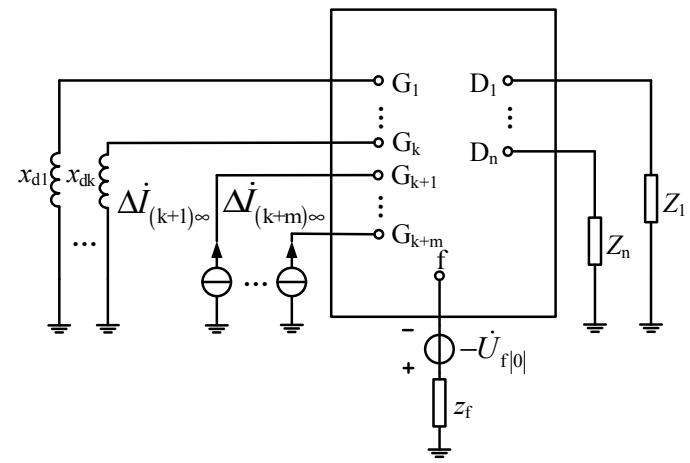

(c)

Figure 10. Normal component network and fault component network of AC components during a fault. (a) normal component network; (b) fault component network during transient period; (c) fault component network during steady period.

As shown in Figure 10a, VSC-based renewable energy injects current $\dot{I}_{|0|}$ towards the node in normal component network and voltage at point $\mathrm{f}$ is normal operation voltage $\dot{U}_{\mathrm{f}|0|}$. Figure $10 \mathrm{~b}, \mathrm{c}$ are fault component networks during transient period and steady period respectively, where voltage source $-\dot{U}_{\mathrm{f}|0|}$ and $z_{\mathrm{f}}$ are added at fault terminal. For conventional power source, short-circuit current calculation is implemented with subtransient reactance $x_{\mathrm{d}}^{\prime \prime}$ and synchronous reactance $x_{\mathrm{d}}$ in fault transient period and steady period, respectively, while VSC-based renewable energy injects current 
towards the node by current sources $\Delta \dot{I}^{\prime}$ and $\Delta \dot{I}_{\infty}$ respectively, and for fault transient period, branch impedance $Z_{c}$ needs adding to VSC-based renewable energy side.

Short-circuit currents of branches are obtained by superposing normal currents and fault components, the former can be obtained through load flow calculation, so only fault components are analyzed. For fault steady period, the equation of node voltage expressed by node impedance matrix $[8,27]$ is as follow:

$$
\Delta U_{i}=Z I_{i}
$$

where:

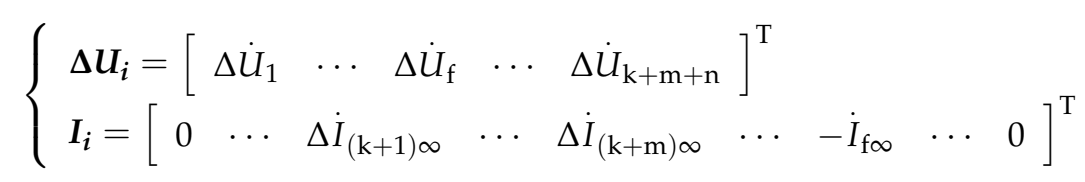

where $\Delta U_{i}$ is fault component of node voltage; $\boldsymbol{I}_{i}$ is injected current towards node $i$; coefficient matrix $\boldsymbol{Z}$ is namely node impedance matrix. The voltage fault component at the fault node $\Delta \dot{U}_{\mathrm{f}}$ in Equation (12) is separately by superposition theorem as follow:

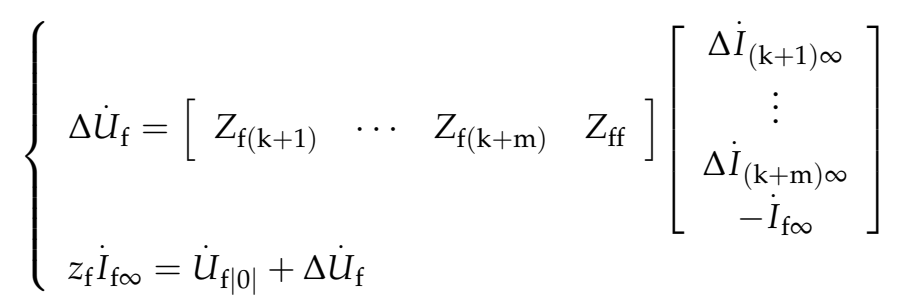

Then, according to Equation (14), AC component of short-circuit current can be obtained as:

$$
\dot{I}_{\mathrm{f} \infty}=\frac{\dot{U}_{\mathrm{f}|0|}+\left[\begin{array}{lll}
Z_{\mathrm{f}(\mathrm{k}+1)} & \cdots & Z_{\mathrm{f}(\mathrm{k}+\mathrm{m})}
\end{array}\right]\left[\begin{array}{c}
\Delta \dot{I}_{(\mathrm{k}+1) \infty} \\
\vdots \\
\Delta \dot{I}_{(\mathrm{k}+\mathrm{m}) \infty}
\end{array}\right]}{Z_{\mathrm{ff}}+z_{\mathrm{f}}}
$$

If diagonal elements of node impedance matrix as well as related mutual impedance are already known, short-circuit current at any short-circuit point can be solved. Short-circuit current $\dot{I}_{\mathrm{f} \infty}$ is substituted into Equation (12) to calculate voltage fault component at any node, then add the normal components to the fault components, post-fault voltage of each node can be obtained as follows:

$$
\dot{U}_{\mathrm{i}}=\dot{U}_{\mathrm{i}|0|}+\Delta \dot{U}_{\mathrm{i}}=\dot{U}_{\mathrm{i}|0|}+\left[\begin{array}{llll}
Z_{\mathrm{i}(\mathrm{k}+1)} & \cdots & Z_{\mathrm{i}(\mathrm{k}+\mathrm{m})} & Z_{\mathrm{if}}
\end{array}\right]\left[\begin{array}{c}
\Delta \dot{I}_{(\mathrm{k}+1) \infty} \\
\vdots \\
\Delta \dot{I}_{(\mathrm{k}+\mathrm{m}) \infty} \\
-\dot{I}_{\mathrm{f} \infty}
\end{array}\right]
$$

Short-circuit current flowing through any branch can be calculated, according to node voltages and branch impedances in the above equation, and thus voltage and current distribution in post-fault network can be obtained. For fault transient period, subtransient reactance is used to replace synchronous reactance in conventional power source, and earth branch $Z_{c}$ should be added to nodes of VSC-based renewable energy to form a new impedance matrix; initial AC component value $I^{\prime}$ of short-circuit current is calculated according to Equations (12)-(16), and its calculation method is similar to that during fault steady period, so unnecessary details will not be given here. 


\subsection{Peak Value Calculation of Three-Phase Short-Circuit Current in Power Systems}

In order to verify dynamic stability of electrical equipment, the peak value of short-circuit current needs to be calculated, at the moment, DC component of short-circuit should be firstly determined. Due to the equivalent circuit for DC short-circuit current is also simplified as a linear electric network [35], the superposition theorem can also be applied to calculate the DC short-circuit current, and then combining the AC and DC short-circuit currents to obtain the peak value of three-phase short-circuit. The VSC-based renewable energy does not inject the DC component into the power grid under normal operation, and the DC fault component of VSC-based renewable energy at node $\mathrm{k}$ can be obtained according to Equation (1), as follows:

$$
\Delta i_{\mathrm{kdc}}(t)=i_{\mathrm{kdc}}(t)=\left(I_{\mathrm{m}|0|} \cos \delta_{0}-I_{\mathrm{m}}^{\prime} \cos \theta_{0}\right) e^{-\frac{t}{T_{\mathrm{ak}}}}
$$

where $T_{\mathrm{ak}}$ is attenuation time constant of DC component for VSC-based renewable energy at node $\mathrm{k}$, and it's related to equivalent impedance of VSC-based renewable energy and network impedance from fault point to the system. For VSC-based renewable energy at different nodes, series circuit between equivalent impedance $Z_{\mathrm{c}}$ and self-impedance $Z_{\mathrm{kk}}$ at grid-connected point can be used to calculate DC attenuation time. Similarly, for a conventional power source at access node $n$, its injected DC component is as follows: $[8,27]$

$$
\Delta i_{\text {ndc }}(t)=i_{\text {ndc }}(t)=-\frac{\sqrt{2} \Delta E_{\mathrm{n}}}{x_{\mathrm{dn}}^{\prime \prime}} \cos \left(\delta_{0}-\theta_{0}\right) e^{-\frac{t}{T_{\mathrm{an}}}}
$$

where $\Delta E_{\mathrm{n}}=E_{\mathrm{n}}^{\prime \prime}-U_{\mathrm{n}}, E_{\mathrm{n}}^{\prime \prime}$ is subtransient potential, $U_{\mathrm{n}}$ is terminal voltage after fault, and $x_{\mathrm{dn}}^{\prime \prime}$ is subtransient reactance; $T_{\text {an }}$ is DC attenuation time of the conventional power source at node $n$, and its calculation method is similar to VSC-based renewable energy. When multiple VSC-based renewable energy is connected to the power grid, as DC component doesn't exist in normal network, and fault network of DC components is just fault component network, as shown in Figure 11.

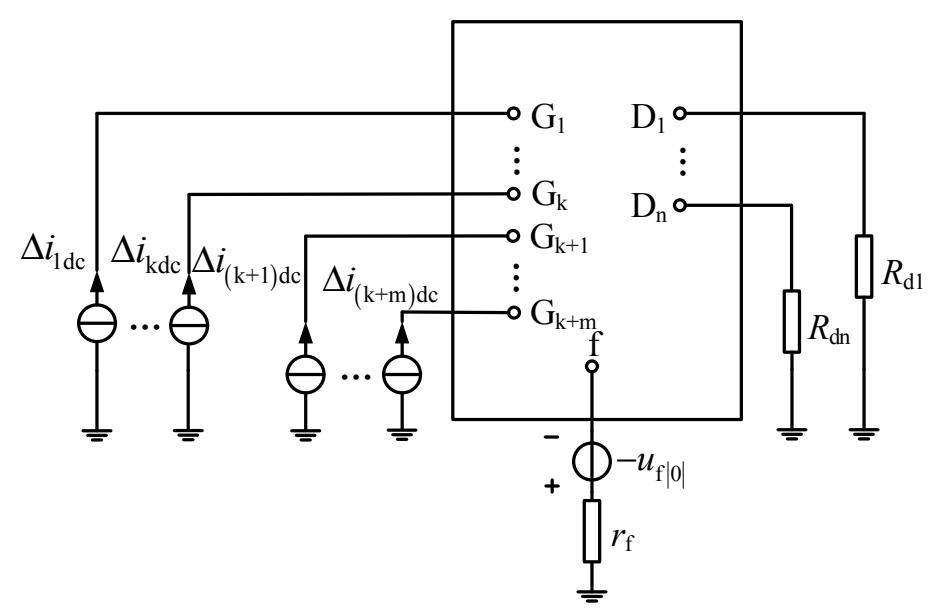

Figure 11. Fault component network of DC components during a fault.

In Figure 11, all of the conventional power sources and VSC-based renewable energy inject DC components by current sources, as DC components don't generate induced potentials through inductances, only resistance parameters are considered in the network. Similar to Equation (12), node voltage equation is expressed as follow:

$$
\Delta u_{i d c}=R i_{i d c}
$$


where

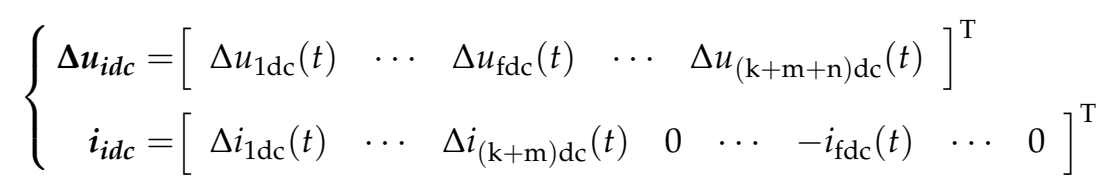

where $\Delta u_{i d c}$ is DC component of node voltage, $i_{i d c}$ is DC component of external injected current at node $i$, coefficient matrix $\boldsymbol{R}$ is namely real part of node impedance matrix $\boldsymbol{Z}$. Similar to the derivation of Equation (15), the DC component of fault point can be obtained as:

$$
i_{\mathrm{fdc}}(t)=\frac{\left[\begin{array}{lll}
R_{\mathrm{f} 1} & \cdots & R_{\mathrm{f}(\mathrm{k}+\mathrm{m})}
\end{array}\right]\left[\begin{array}{c}
\Delta i_{1 \mathrm{dc}}(t) \\
\vdots \\
\Delta i_{(\mathrm{k}+\mathrm{m}) \mathrm{dc}}(t)
\end{array}\right]}{R_{\mathrm{ff}}+r_{\mathrm{f}}}
$$

The peak value is estimated under the severest situation, using AC component and DC component of short-circuit current during transient period. In consideration of the most serious short-circuit, it is assumed that the system is under no-load operation before fault, and instantaneous short-circuit current value reaches maximum within half a cycle after fault, namely $t=0.01 \mathrm{~s}$. Then, the peak value $i_{\mathrm{fM}}$ at fault point and its effective value $I_{\mathrm{fM}}$ are as follows:

$$
\left\{\begin{array}{l}
i_{\mathrm{fM}}=\sqrt{2} I_{\mathrm{f}}^{\prime}+i_{\mathrm{fdc}}(0.01) \\
I_{\mathrm{fM}}=\sqrt{I_{\mathrm{f}}^{\prime 2}+i_{\mathrm{fdc}}^{2}(0.01)}
\end{array}\right.
$$

where $I_{\mathrm{f}}^{\prime}$ is initial AC component value of short-circuit current, and $i_{\mathrm{fdc}}(0.01)$ is DC component value of $0.01 \mathrm{~s}$ after fault.

Fault characteristics of VSC-based renewable energy are different from those of conventional power sources. Through the analysis of short-circuit current expression of VSC-based renewable energy, its fault process can be divided into transient and steady states, where transient state includes AC component attenuation and DC component attenuation. During short-circuit current calculation of power grid with high penetration of VSC-based renewable energy, equivalent impedances, and equivalent internal potentials under different voltage drops are obtained through experimental test, mutual iterations of transient equivalent model and network equation are implemented to update fault components of short-circuit current, and then AC and DC components of three-phase short-circuit in the network can be obtained accurately.

In order to simplify engineering calculation process, considering the severest situation, as post-fault $I_{\mathrm{m}}^{\prime}$ will not exceed $I_{\max }$, and transient current $I_{\mathrm{m}}^{\prime}$ of VSC-based renewable energy is taken as $I_{\max }$ in this paper; $I_{\mathrm{m} \infty}$ can be solved through power reference values $P^{*}, Q^{*}$ and command current. They are substituted into fault component equations of $A C$ and DC components, respectively; the initial values and steady values of AC components, as well as DC components at different moments can be calculated by superposition theorem. Then the peak value is estimated by initial AC component values and DC component values, which is used to guide equipment selection and dynamic stability test.

\section{Simulation Analysis}

Renewable energy installed capacity proportions of Huainan power grid and Huaisu power grid are $64 \%$ and $44 \%$ relative to the maximum load in 2018 , both of which have reached high permeability levels. Taking grid structures and parameters of Huainan and Huaisu power grid as examples, the proposed method is used to calculate short-circuit currents under different fault nodes, meanwhile a simulation model in MATLAB/Simulink is established, calculated results and simulation results are compared, and the correctness of the proposed method is verified. As influence of load on short-circuit current is usually neglected in practical calculation, the following examples have completed calculation and simulation under no-load conditions before fault. 
Photovoltaic power stations in the calculated examples all consist of $500 \mathrm{~kW}$ photovoltaic generating sets, where rated voltage of each generating set is $315 \mathrm{~V}$, power factor is 1 (main parameters are shown in Appendix A), upper limit output current of each photovoltaic inverter is 1.5 times of rated current, and voltages of generating units rise to $35 \mathrm{kV}$ through step-up transformers. As impedances of collecting power lines for photovoltaic power stations are small, detailed collecting power lines will not be taken into account in calculated examples.

\section{1. $500 \mathrm{kV}$ Case in Huainan Area}

Calculation and simulation analysis are carried out for $500 \mathrm{kV}$ grid structure of Huainan power grid, and its network structure is shown in Figure 12. In Figure 12a, green points represent $220 \mathrm{kV}$ substations, and red points represent $500 \mathrm{kV}$ substations, including Fengtai, Tangzhuang, Gaocheng, Luochang, Kongdian, and Feibei. Green filled area in the point represents grid-connected point of photovoltaic, and photovoltaic allowed capacity is labeled and filled by yellow. Simplified structure is shown in Figure 12b, 480 MW and 960 MW photovoltaic power stations are connected into Tangzhuang and Gaocheng, respectively, and the impedance parameters of all branches are shown in Table 2. Considering fluctuation of photovoltaic power generations with light illumination in actual operation, illumination intensities, input by all photovoltaic power generations, in normal operation and after fault are all selected as $1000 \mathrm{~W} / \mathrm{m}^{2}$ in simulation, input environmental temperature is $30{ }^{\circ} \mathrm{C}$, and output power of photovoltaic power generation is mainly determined by illumination intensity.

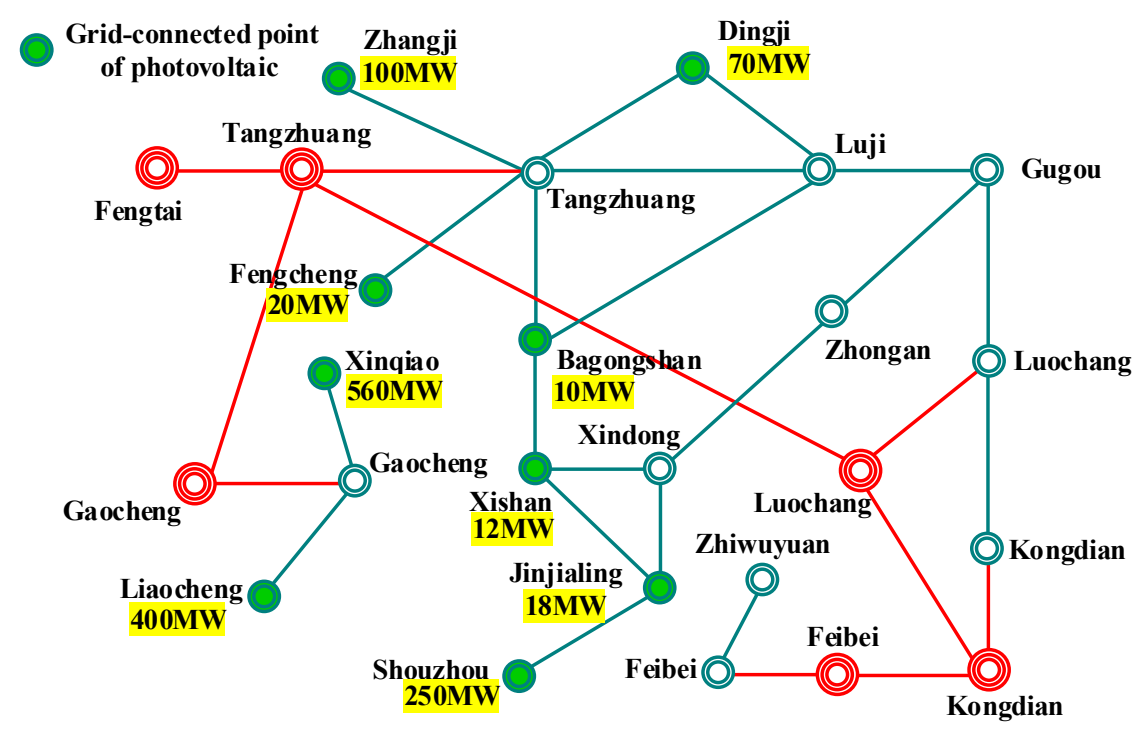

(a)

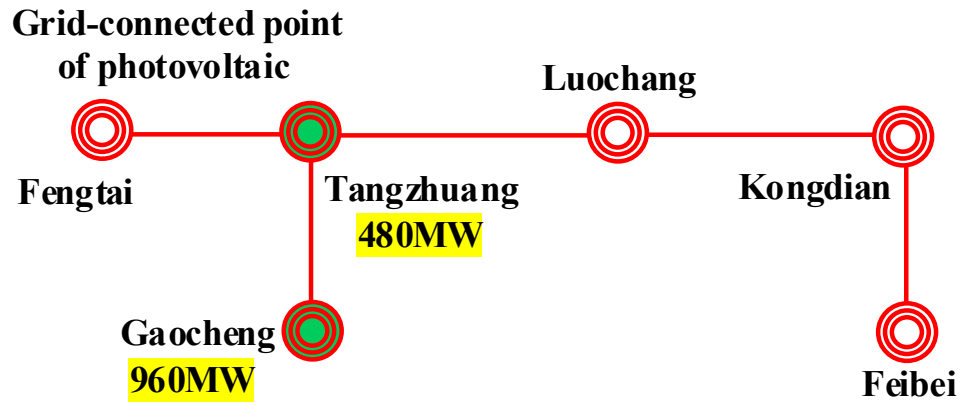

(b)

Figure 12. Single line diagram of Huainan $500 \mathrm{kV}$ power grid. (a) overall structure; (b) simplified structure. 
Table 2. $500 \mathrm{kV}$ branch impedance parameters.

\begin{tabular}{cccc}
\hline $\begin{array}{c}\text { Equivalent Impedance between } \mathbf{5 0 0} \mathbf{~ k V} \\
\text { Busbars Benchmark Capacity }=\mathbf{1 0 0} \mathbf{~ M V A}\end{array}$ & \multicolumn{2}{c}{ Positive Sequence Impedance } \\
\hline Busbar I & Busbar J & $\mathbf{R 1}(\mathbf{p u )}$ & $\mathbf{X 1} \mathbf{( p u )}$ \\
\hline Feibei & Gaocheng & 0.0003 & 0.0089 \\
Feibei & Kongdian & 0.0002 & 0.0035 \\
Feibei & Luochang & 0.0016 & 0.0238 \\
Fengtai & Tangzhuang & 0.0001 & 0.001 \\
Gaocheng & Kongdian & 0.0170 & 0.1538 \\
Gaocheng & Luochang & 0.0014 & 0.0212 \\
Gaocheng & Tangzhuang & 0.0004 & 0.0072 \\
Kongdian & Luochang & 0.0001 & 0.0011 \\
Luochang & Tangzhuang & 0.0004 & 0.0051 \\
\hline
\end{tabular}

In order to further verify the accuracy and correctness of the calculation method proposed in this paper, a conventional method, which treats VSC-based renewable energy as conventional voltage sources, is used to compare with the proposed method in this paper, and values of steady short-circuit currents and initial AC component are calculated when three-phase short-circuit happens to 6 substations respectively, finally a comparative verification is implemented with simulation data. During transient and steady calculation processes, 1.5 and 1.3 times of rated output currents are respectively taken for VSC-based renewable energy in conventional method, and results are solved as seen in Figure 13.

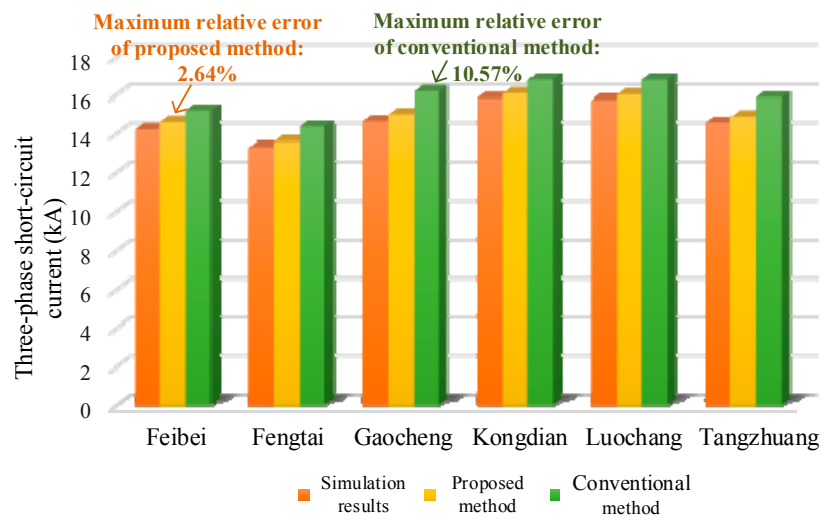

(a)

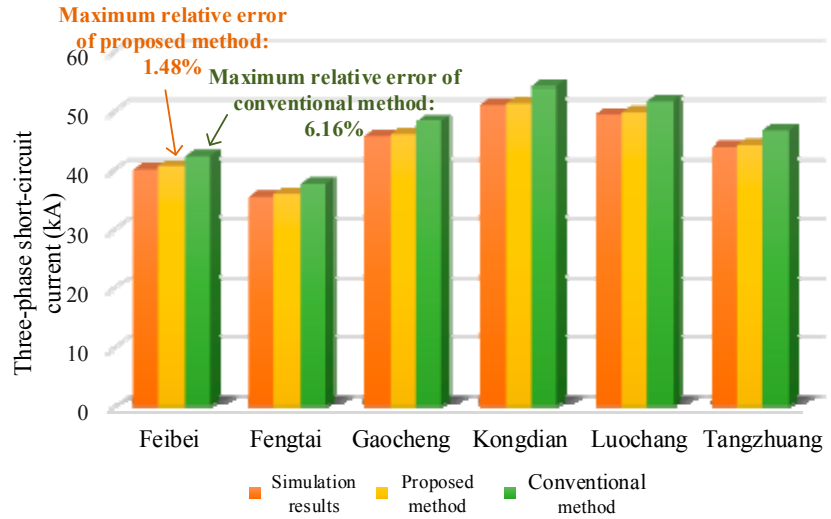

(b)

Figure 13. Three-phase short-circuit current of substations. (a) steady short-circuit current; (b) initial AC component value. 
In Figure 13a, steady short-circuit current values calculated through two different methods are compared with simulation data, and it can be seen from histogram that the proposed method in this paper is closer to simulation results, and maximum relative error is $2.64 \%$, which is lower than $8.33 \%$ of the conventional method. Figure 13b shows comparison results of initial AC component values, and relative error of the proposed method doesn't exceed $1.48 \%$, which is still lower than $6.16 \%$ of conventional method. Based on a comparison from the angle of mean error, mean error of this method, and conventional method are $0.92 \%$ and $5.74 \%$, respectively, and it further certifies that this method is more accurate than conventional method. Moreover, by comparing Figure 13a,b, it can be found that mean error $0.92 \%$, during calculation of initial AC component value, is smaller than mean error $2.1 \%$ of steady short-circuit current in this method, which embodies the superiority of this method in calculation of fault transient period.

Taking Kongdian substation as an example, short-circuit DC component is calculated, which is used to evaluate the peak value with initial AC component value. Calculated results that were obtained through two methods are compared with simulation waveform data, as shown in Figure 14. In conventional method, impulse coefficient $K_{\mathrm{M}}$ is used to multiply by initial AC component value for approximate estimation of peak value, namely $K_{M}=1.8$. In Figure 14 , post-fault $0.01 \mathrm{~s}$ is taken as maximum instantaneous value of short-circuit value, namely peak value, black square represents simulation data, while red and green squares represent calculation results of this method and conventional method respectively. It can be known from this figure that results of this method are closer to simulation results, but the conventional method has a certain deviation, and then it's proved that this method contributes more to accurate evaluation of peak value at fault point.

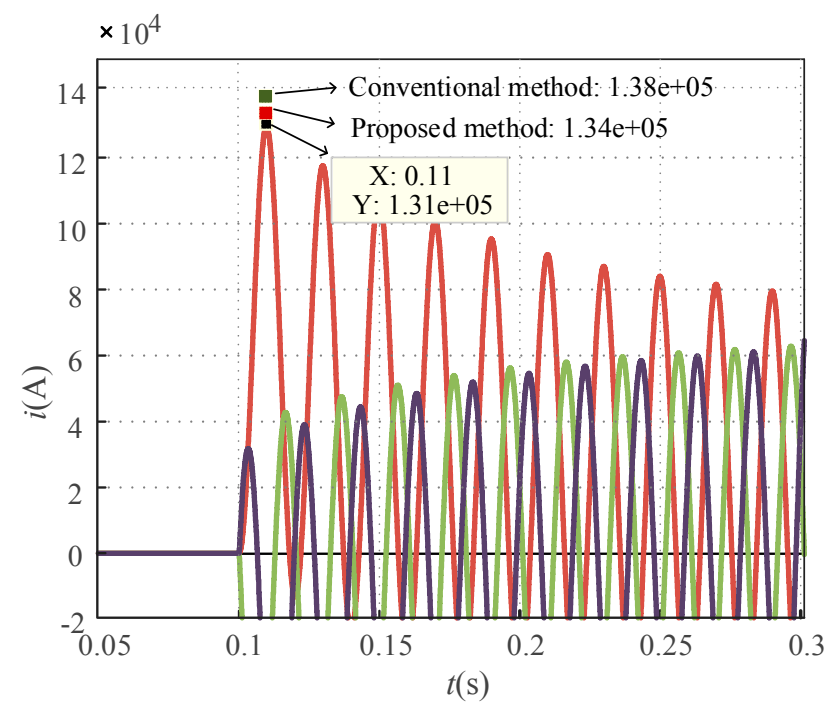

Figure 14. Three-phase short-circuit current of Kongdian substation.

In Figure 13b, the initial AC component value in Kongdian substation is close to $50 \mathrm{kA}$, which may be exceeding the allowable value. At the moment, short-circuit current level can be limited by reducing the photovoltaic allowed capacity. Assume the original scheme is with the photovoltaic capacity in Figure 12, and the modified scheme is reduced all photovoltaic capacity to 0.6 times of that in the original scheme. The comparison of initial AC component values between the original scheme and the modified scheme is shown in Figure 15. When the photovoltaic capacities reduce, the short-circuit current of each substation decreases with different degrees, and the short-circuit current of Kongdian substation is much less than the allowable value of $50 \mathrm{kA}$. The substation closer to grid-connected point of photovoltaic, the change of photovoltaic capacity will have a greater effect on its short-circuit current. 


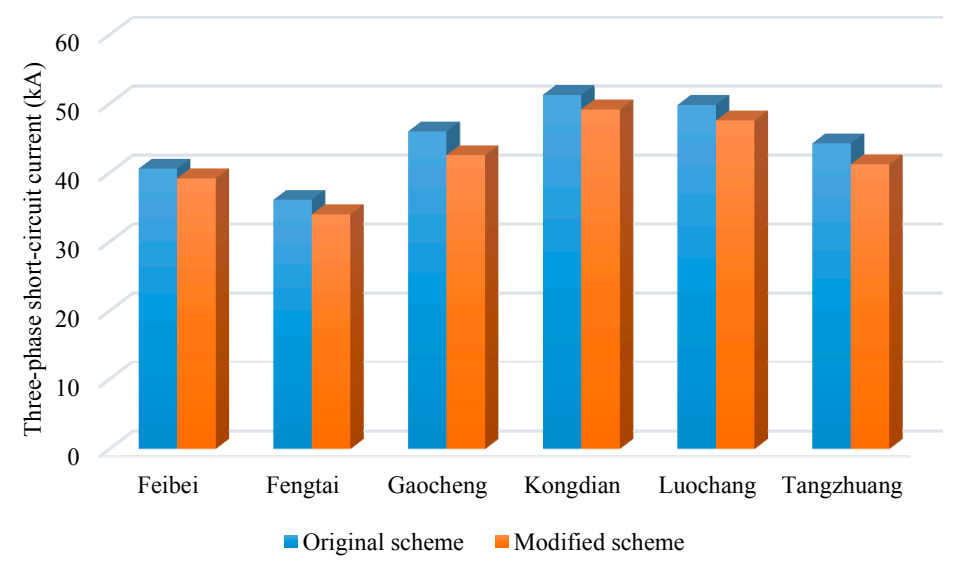

Figure 15. Comparison of initial AC component values of Huainan power grid.

\section{2. $220 \mathrm{kV}$ Case in Huaisu Area}

220 kV Huaisu power grid mainly includes 35 substations, like Suixi, Nanping, and Huaibei substations, and its main structure is shown in Figure 16. Green filled area in the point represents grid-connected point of photovoltaic, photovoltaic allowed capacity is labeled and filled by yellow, and it can be seen from the figure that photovoltaic connection presents features of large quantity and dispersity, and branch impedance parameters in all of the substations are listed in Appendix B.

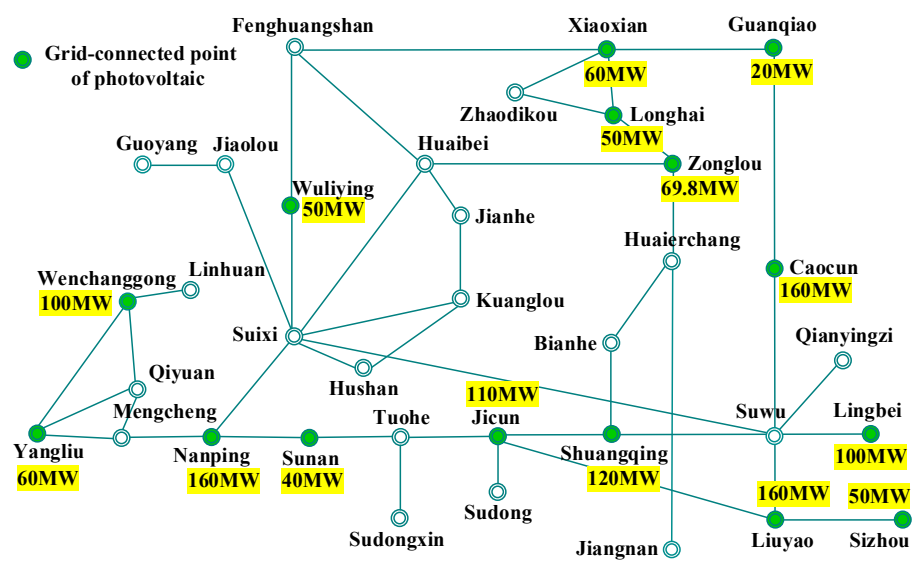

Figure 16. Single line diagram of Huaisu $220 \mathrm{kV}$ power grid.

As there are a great number of nodes in this calculated example, calculation results of only some nodes are listed in this paper, and details are seen in Figure 17. Each sector area, in Figure 17a, is corresponding to calculation result of initial AC component value of one substation, length of sector radius represents short-circuit current value, and different colors represent results obtained through different methods. According to sector areas with different colors that are shown in the figure, it can be known that calculation results obtained through the method proposed in this paper are closest to simulation data, its sector area nearly overlaps with simulation result. But there is some deviation in calculated results obtained through conventional method, comparing with simulation results, where maximum absolute error of conventional method reaches $2.31 \mathrm{kA}$, while that of the proposed method is only $0.36 \mathrm{kA}$. Comparison of relative errors of two methods is shown in Figure 17b, and maximum relative error of the method proposed in this paper doesn't exceed $2 \%$, while that of conventional method reaches as high as $7 \%$. The above data have further verified initial AC component values, obtained through the proposed method, are more accurate and are also applicable to complex power systems. 


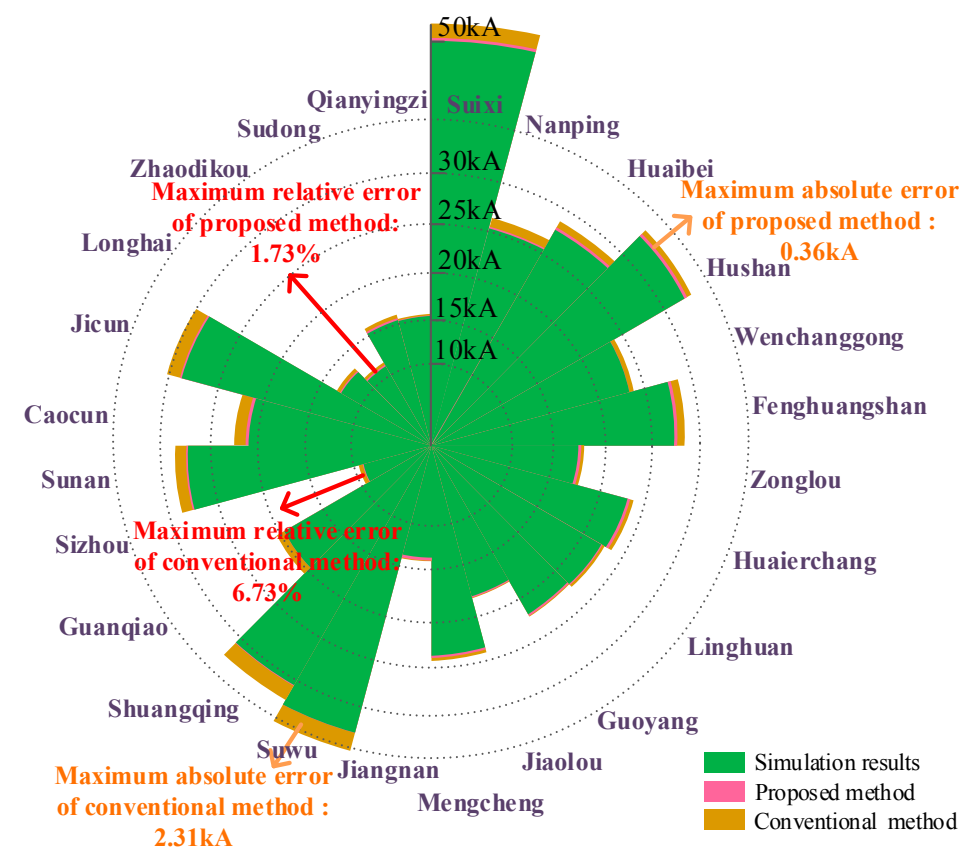

(a)

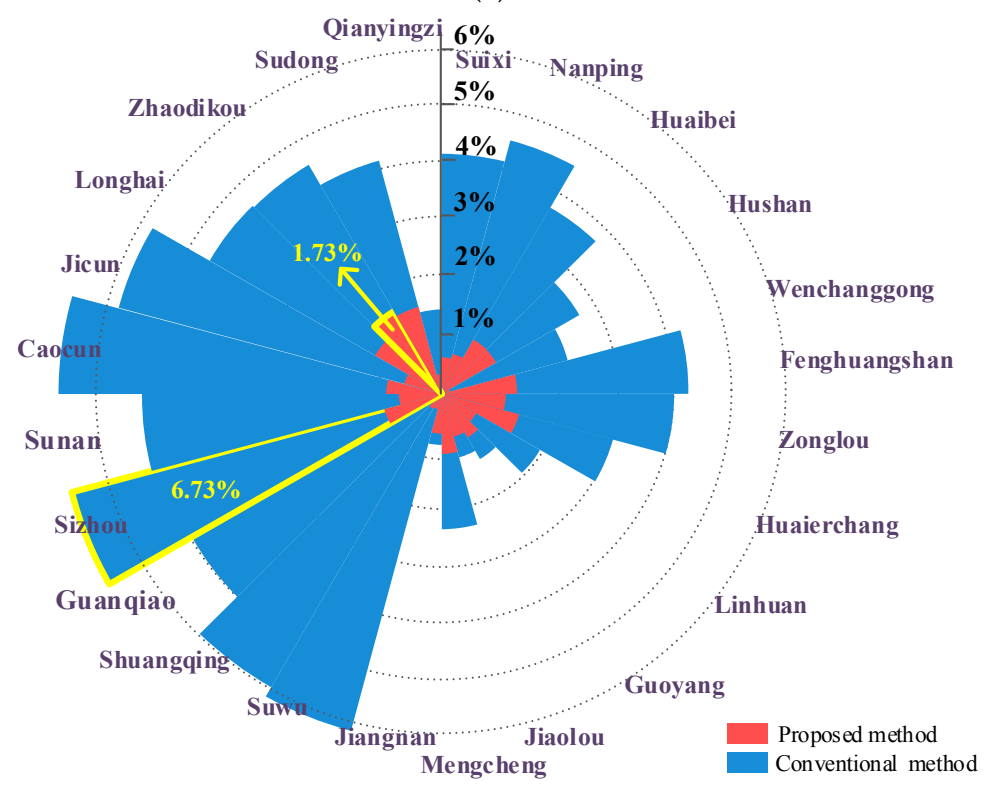

(b)

Figure 17. Initial value of AC component of substations. (a) initial AC component value; (b) comparison of relative errors of initial AC components.

Similar to Section 3.1, impulse coefficient $K_{\mathrm{M}}=1.8$ is taken in conventional method to evaluate peak value, and its comparison with calculation results obtained through the method in this paper is as shown in Figure 18. Difference between calculation result of conventional method and simulation result is larger, and maximum relative error reaches as high as $22.98 \%$, but relative error of the method proposed in this paper doesn't exceed $10 \%$, which is within acceptable range. 


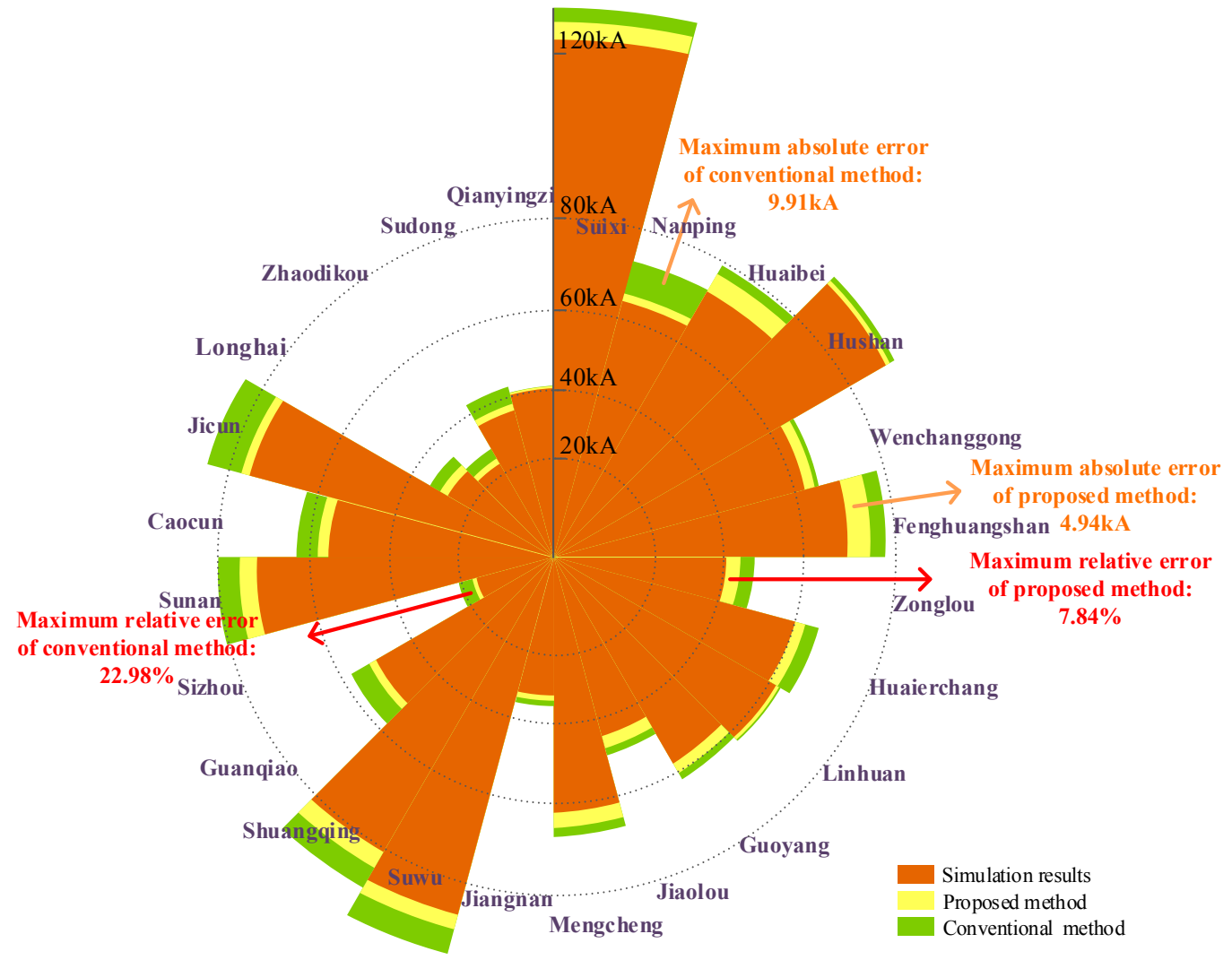

Figure 18. The peak value of short-circuit current of substations.

It can be known from the above analyses that, the calculation method in this paper is reasonably effective for three-phase short-circuit current calculation of complex power system with high penetration of VSC-based renewable energy. From simple network to complex network, structural parameters of Huainan and Huaisu power grids are used to verify accuracy of the proposed method. This method is suitable for three-phase short-circuit current calculation of complex systems, and initial AC component value and peak value can be accurately evaluated.

Due to the connection of photovoltaic in adjacent substations, the initial AC component value of Suixi is close to the allowable value of $50 \mathrm{kA}$, in Figure 17a. By moving the adjacent photovoltaic substations of Wuliying and Nanping to Jiangnan, which is far from Suixi, a modified scheme is shown in Figure 19 to restrain the short-circuit current of Suixi. The initial AC component values of the original scheme in Figure 16 and the modified scheme in Figure 19 are compared in Figure 20. It can be known the short-circuit current of Suixi substation is effectively limited, and the short-circuit current of Nanping is also reduced, while the short-circuit current of Jiangnan has been increased by a small amplitude. The short-circuit current does not exceed the interrupting capacity of breakers, so the proposed method of short-circuit current calculation can be used to achieve the grid-connected scheme of VSC-based renewable energy when considering short-circuit current limitation constraints. 


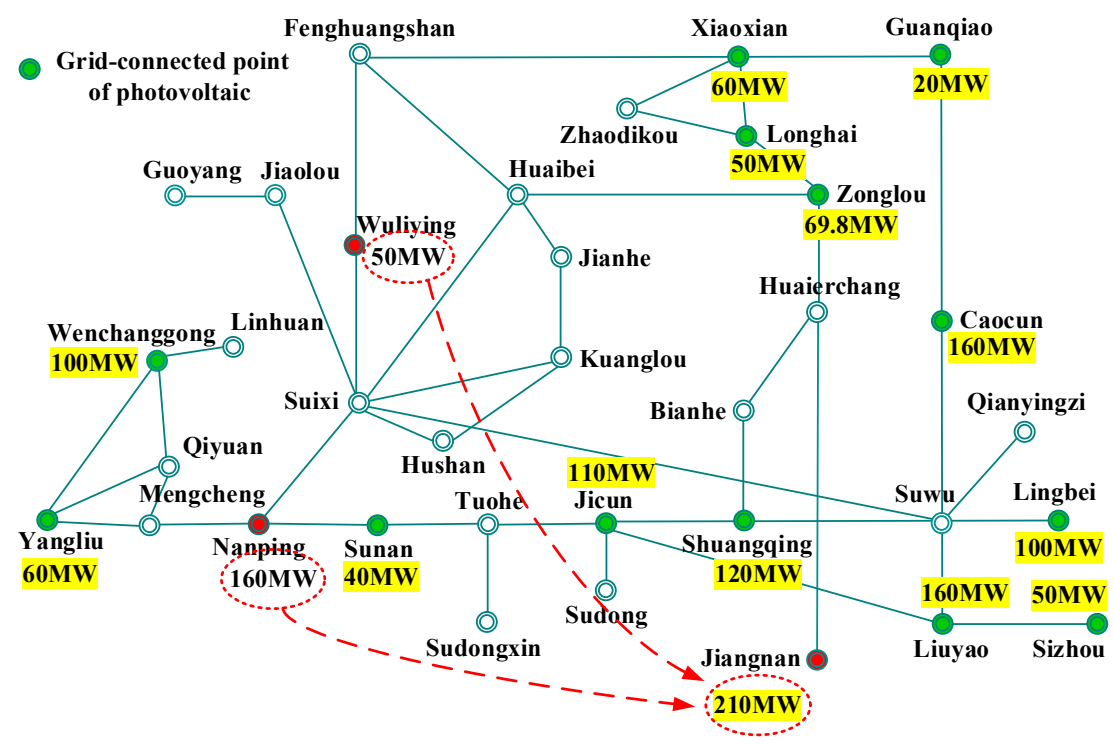

Figure 19. A modified scheme of the connection of photovoltaic power stations in Huaisu power grid.

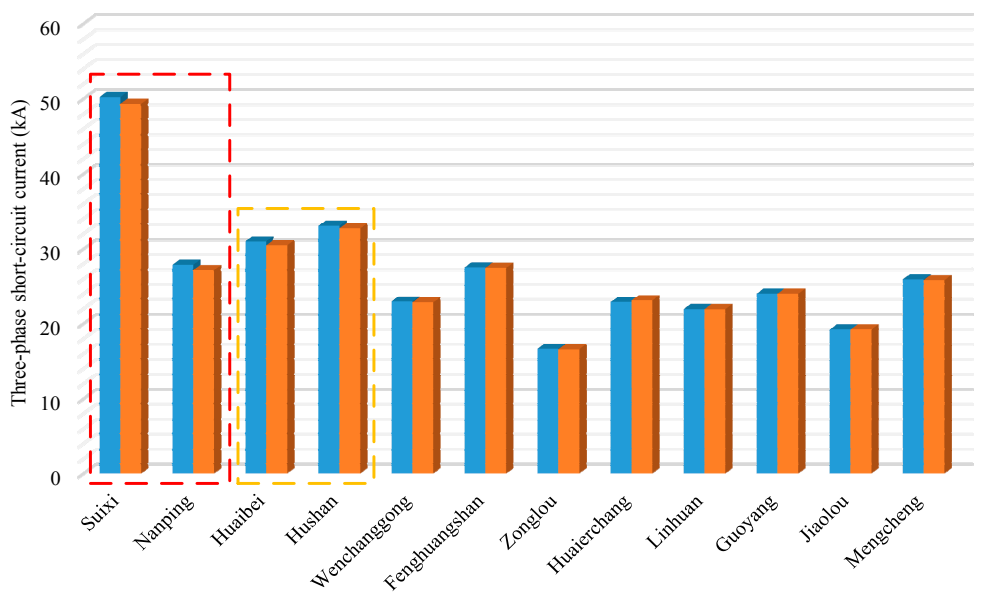

(a)

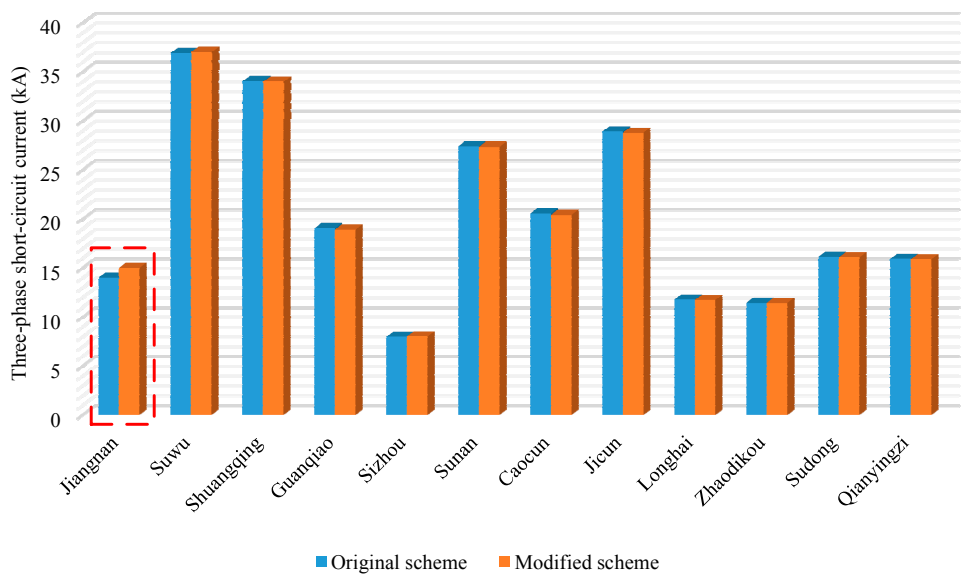

(b)

Figure 20. Comparison of initial AC component values of Huaisu power grid. (a) short-circuit current of substations (from Suixi to Mengcheng); (b) short-circuit current of substations (from Jiangnan to Qianyingzi). 


\section{Conclusions}

In this paper, measured short-circuit current waveforms of a VSC-based renewable energy was firstly analyzed, and then a full current expression was acquired, based on which superposition theorem was used to derive three-phase short-circuit AC and DC components, respectively, and then calculation method of three-phase short-circuit current was proposed, so as to obtain peak value. A simulation model was established in MATLAB/Simulink, through analysis of calculated examples-Anhui $500 \mathrm{kV}$ and $220 \mathrm{kV}$ power grids, it is verified that the proposed method could effectively calculate initial short-circuit AC component and peak value. The study shows that short-circuit current of a VSC-based renewable energy mainly consists of three parts: attenuated periodic AC component, steady short-circuit current and attenuated DC component. As VSC-based renewable energy has unique fault characteristics, its output current after fault is incorporated into fault component network, a corresponding impedance matrix is formed specific to different equivalent circuits in fault steady and transient states, and then a superposition theorem is used to accurately evaluate three-phase short-circuit current, so as to provide a basis for grid planning and design, short-circuit current management as well as protection calculation.

Acknowledgments: This work was supported by the Chongqing Research Program of Basic Research and Frontier Technology (cstc2015jcyjBX0033) and National Natural Science Foundation of China (51577018).

Author Contributions: Qianggang Wang and Jiafang Wu contributed to paper writing and the whole revision process. Niancheng Zhou and Jiafang Wu built the simulation model and analyzed the data. All the authors have read and approved the final manuscript.

Conflicts of Interest: The authors declare no conflict of interest.

Appendix A. Related Parameters of PV Generator Set

Table A1. Basic parameters of PV generator set.

\begin{tabular}{cc}
\hline Type & Photovoltaic Grid-Connected Inverter \\
\hline Model number & SG500MX-M \\
Rated AC output power & $500 \mathrm{~kW}$ \\
Rated frequency & $50 \mathrm{~Hz}$ \\
Maximum output voltage (VDC) & $1000 \mathrm{~V}$ \\
MPPT voltage range (VDC) & $480 \sim 850 \mathrm{~V}$ \\
Rated grid voltage (VAC) & $315 \mathrm{~V}$ \\
Maximum continuous working current & $1018 \mathrm{~A}$ \\
The power factor & $\geq 0.99$ \\
\hline
\end{tabular}

Appendix B. Branch Impedance Parameters of 220 kV Network

Table A2. $220 \mathrm{kV}$ branch impedance parameters.

\begin{tabular}{cccc}
\hline $\begin{array}{c}\text { Equivalent Impedance between } \\
\text { Benchmark Capacity }\end{array}$ & $\mathbf{1 0 0} \mathbf{~ M V A}$ & \multicolumn{2}{c}{ Bositive Sequence Impedance } \\
\hline Busbar I & Busbar J & $\mathbf{R 1} \mathbf{( p u )}$ & $\mathbf{X 1} \mathbf{( p u )}$ \\
\hline Zonglou & Longhai & 0.009 & 0.0472 \\
Zonglou & Huaierchang & 0.0059 & 0.0312 \\
Zonglou & Huaibei & 0.0037 & 0.018 \\
Xiaoxian & Longhai & 0.0071 & 0.0361 \\
Xiaoxian & Guanqiao & 0.0014 & 0.0115 \\
Xiaoxian & Fenghuangshan & 0.0026 & 0.0134 \\
Xiaoxian & Zhaodikou & 0.0031 & 0.026 \\
Yangliu & Wenchanggong & 0.0026 & 0.0214 \\
Yangliu & Qiyuan & 0.0018 & 0.0145 \\
Yangliu & Mengcheng & 0.0069 & 0.037 \\
Wuliying & Suixi & 0.0008 & 0.0038 \\
Wuliying & Fenghuangshan & 0.0015 & 0.0077 \\
\hline
\end{tabular}


Table A2. Cont.

\begin{tabular}{|c|c|c|c|}
\hline \multicolumn{2}{|c|}{$\begin{array}{c}\text { Equivalent Impedance between } 220 \mathrm{kV} \text { Busbars } \\
\text { Benchmark Capacity = } 100 \mathrm{MVA}\end{array}$} & \multicolumn{2}{|c|}{ Positive Sequence Impedance } \\
\hline Busbar I & Busbar J & R1 (pu) & $\mathrm{X} 1$ (pu) \\
\hline Guoyang & Wenchanggong & 0.0038 & 0.0317 \\
\hline Guoyang & Suixi & -0.1381 & 1.0474 \\
\hline Guoyang & Mengcheng & 0.0105 & 0.0794 \\
\hline Guoyang & Jiaolou & 0.0011 & 0.0058 \\
\hline Guoyang & Jiangnan & -0.1284 & 1.8228 \\
\hline Wenchanggong & Suixi & -1.7936 & 7.5312 \\
\hline Wenchanggong & Qiyuan & 0.0054 & 0.0399 \\
\hline Wenchanggong & Mengcheng & 0.0207 & 0.4638 \\
\hline Wenchanggong & Linhuan & 0.0004 & 0.0056 \\
\hline Wenchanggong & Jiangnan & -2.3867 & 13.3188 \\
\hline Tuohe & Sunan & 0.0001 & 0.0012 \\
\hline Tuohe & Sudongxin & 0.0005 & 0.0038 \\
\hline Tuohe & Jicun & 0.0002 & 0.0013 \\
\hline Suixi & Suwu & 0.0006 & 0.009 \\
\hline Suixi & Nanping & 0.0028 & 0.0143 \\
\hline Suixi & Mengcheng & -0.0662 & 0.9864 \\
\hline Suixi & Kuanglou & 0.0002 & 0.0032 \\
\hline Suixi & Jiaolou & 0.0071 & 0.0359 \\
\hline Suixi & Jiangnan & -0.0036 & 0.2195 \\
\hline Suixi & Huaibei & 0.0045 & 0.023 \\
\hline Suixi & Hushan & 0.0006 & 0.0079 \\
\hline Suwu & Liuyao & 0.0041 & 0.0226 \\
\hline Suwu & Lingbei & 0.0016 & 0.013 \\
\hline Suwu & Shuangqing & 0.0003 & 0.0026 \\
\hline Suwu & Caocun & 0.0012 & 0.0098 \\
\hline Suwu & Qianyingzi & 0.0015 & 0.0179 \\
\hline Sunan & Nanping & 0.0024 & 0.0123 \\
\hline Sudong & Jicun & 0.0014 & 0.0069 \\
\hline Sizhou & Liuyao & 0.0026 & 0.0134 \\
\hline Qiyuan & Mengcheng & 0.0015 & 0.0121 \\
\hline Nanping & Mengcheng & 0.0036 & 0.0184 \\
\hline Mengcheng & Jiangnan & 0.0831 & 1.3231 \\
\hline Longhai & Zhaodikou & 0.0008 & 0.0038 \\
\hline Liuyao & Jicun & 0.0091 & 0.0461 \\
\hline Kuanglou & Jianhe & 0.0005 & 0.0043 \\
\hline Kuanglou & Hushan & 0.0008 & 0.0111 \\
\hline Jiangnan & Huaierchang & 0.0069 & 0.0349 \\
\hline Jianhe & Huaibei & 0.0005 & 0.003 \\
\hline Jicun & Shuangqing & 0.0014 & 0.0069 \\
\hline Huaierchang & Bianhe & 0.0018 & 0.0092 \\
\hline Huaibei & Fenghuangshan & 0.0015 & 0.0077 \\
\hline Guanqiao & Caocun & 0.0004 & 0.0036 \\
\hline Bianhe & Shuangqing & 0.0014 & 0.0073 \\
\hline
\end{tabular}

\section{References}

1. Schellekens, G.; Battaglini, A.; Lilliestam, J.; McDonnell, J.; Patt, A. 100\% Renewable Electricity: A Roadmap to 2050 for Europe and North Africa; PricewaterhouseCoopers: London, UK, 2010.

2. Mai, T.; Wiser, R.; Sandor, D.; Brinkman, G.; Heath, G.; Denholm, P.; Hostick, D.J.; Darghouth, N.; Schlosser, A.; Strzepek, K. Renewable Electricity Futures Study. Volume 1: Exploration of High-Penetration Renewable Electricity Futures; Office of Scientific \& Technical Information Technical Reports; National Renewable Energy Laboratory: Golden, CO, USA, 2017.

3. Elliston, B.; Diesendorf, M.; MacGill, I. Simulations of scenarios with $100 \%$ renewable electricity in the Australian National Electricity Market. Energy Policy 2012, 45, 606-613. [CrossRef]

4. Li, H.; Eseye A, T.; Zhang, J.; Zheng, D. Optimal energy management for industrial microgrids with high-penetration renewables. Prot. Control Mod. Power Syst. 2017, 2, 12. [CrossRef]

5. Wang, Q.; Zhou, N.; Ye, L. Fault analysis for distribution networks with current-controlled three-phase inverter-interfaced distributed generators. IEEE Trans. Power Deliv. 2015, 30, 1532-1542. [CrossRef] 
6. Kong, X.; Zhang, Z.; Yin, X.; Wen, M. Study of fault current characteristics of the DFIG considering dynamic response of the RSC. IEEE Trans. Energy Convers. 2014, 29, 278-287.

7. Castilla, M.; Miret, J.; Sosa, J.L.; Matas, J.; de Vicuña, L.G. Grid-fault control scheme for three-phase photovoltaic inverters with adjustable power quality characteristics. IEEE Trans. Power Electron. 2010, 25, 2930-2940. [CrossRef]

8. Chapman, S.J. Electric Machinery and Power System Fundamentals; McGraw-Hill: New York, NY, USA, 2000.

9. Rizzo, R.; Piegari, L.; Tricoli, P. A comparison between line-start synchronous machines and induction machines in distributed generation. Prz. Elektrotech. 2012, 88, 187-189.

10. Ouhrouche, M. Transient analysis of a grid connected wind driven induction generator usingareal-time simulation platform. Renew. Energy 2009, 34, 801-806. [CrossRef]

11. Rashid, G.; Ali, M.H. A Modified Bridge-Type Fault Current Limiter for Fault Ride-Through Capacity Enhancement of Fixed Speed Wind Generator. IEEE Trans. Energy Convers. 2014, 29, 527-534.

12. Moghadasi, A.; Sarwat, A.; Guerrero, J.M. A comprehensive review of low-voltage-ride-through methods for fixed-speed wind power generators. Renew. Sustain. Energy Rev. 2016, 55, 823-839. [CrossRef]

13. Guo, W.; Xiao, L.; Dai, S. Fault current limiter-battery energy storage system for the doubly-fed induction generator: Analysis and experimental verification. IET Gener. Transm. Distrib. 2016, 10, 653-660. [CrossRef]

14. Shuai, Z.; Shen, C.; Yin, X.; Shen, J. Fault analysis of inverter-interfaced distributed generators with different control schemes. IEEE Trans. Power Deliv. 2017. [CrossRef]

15. Liu, Z.; Liu, J. Indirect current control based seamless transfer of three-phase inverter in distributed generation. IEEE Trans. Power Electron. 2014, 29, 3368-3383. [CrossRef]

16. Pan, Y.; Ren, W.; Ray, S.; Walling, R.; Reichard, M. Impact of inverter interfaced distributed generation on overcurrent protection in distribution systems. In Proceedings of the IEEE Power Engineering and Automation Conference, Wuhan, China, 8-9 September 2011; pp. 371-376.

17. Kong, X.; Yuan, Y.; Li, P.; Wang, Y. Study on the fault current transient features of the PV inverter. In Proceedings of the International Conference on Renewable Power Generation, Beijing, China, 17-18 October 2015.

18. Baran, M.E.; El-Markaby, I. Fault analysis on distribution feeders with distributed generators. IEEE Trans. Power Syst. 2005, 20, 1757-1764. [CrossRef]

19. Plet, C.A.; Brucoli, M.; Mcdonald, J.D.F.; Green, T.C. Fault models of inverter-interfaced distributed generators: Ex-perimental verification and application to fault analysis. In Proceedings of the IEEE Power and Energy Society General Meeting, Detroit, MI, USA, 24-29 July 2011; pp. 1-8.

20. Guo, W.; Mu, L.; Zhang, X. Fault models of inverter-interfaced distributed generators within a low-voltage microgrid. IEEE Trans. Power Deliv. 2017, 32, 453-461. [CrossRef]

21. Baghaee, H.R.; Mirsalim, M.; Gharehpetian, G.B.; Talebi, H.A. A new current limiting strategy and fault model to improve fault ride-through capability of inverter interfaced DERs in autonomous microgrids. Sustain. Energy Technol. Assess. 2017, 24, 71-81. [CrossRef]

22. Tristiu, I.; Bulac, C.; Costinas, S.; Toma, L.; Mandiş, A.; Zăbavă, T. A new and efficient algorithm for short-circuit calculation in distribution networks with distributed generation. In Proceedings of the 2015 9th International Symposium on Advanced Topics in Electrical Engineering (ATEE), Bucharest, Romania, 7-9 May 2015; pp. 816-821.

23. Plet, C.A.; Green, T.C. Fault response of inverter interfaced distributed generators in grid-connected applications. Electr. Power Syst. Res. 2014, 106, 21-28. [CrossRef]

24. Yang, S.; Tong, X. Integrated Power Flow and Short Circuit Calculation Method for Distribution Network with Inverter Based Distributed Generation. Math. Probl. Eng. 2016, 2016, 9404951. [CrossRef]

25. Tu, D.V.; Chaitusaney, S. Impacts of inverter-based distributed generation control modes on short-circuit currents in distribution systems. In Proceedings of the 20127 th IEEE Conference on Industrial Electronics and Applications (ICIEA), Singapore, 18-20 July 2012; pp. 1645-1650.

26. Tu, D.V.; Chaitusaney, S.; Yokoyama, A. Fault current calculation in distribution systems with inverter-based distributed generations. IEEJ Trans. Electr. Electron. Eng. 2013, 8, 470-477.

27. Belkhayat, M.; Edwards, J.; Hoonchareon, N.; Marte, O.; Stenberg, D.; Walters, E. Transients in Power Systems; Wiley: New York, NY, USA, 2001.

28. He, J.; Li, Y.W. Generalized closed-loop control schemes with embedded virtual impedances for voltage source converters with LC or LCL filters. IEEE Trans. Power Electron. 2012, 27, 1850-1861. [CrossRef] 
29. Wang, X.; Blaabjerg, F.; Chen, Z. Autonomous control of inverter-interfaced distributed generation units for harmonic current filtering and resonance damping in an islanded microgrid. IEEE Trans. Ind. Appl. 2014, 50, 452-461. [CrossRef]

30. Wu, T.; Liu, Z.; Liu, J.; Wang, S.; You, Z. A unified virtual power decoupling method for droop-controlled parallel inverters in microgrids. IEEE Trans. Power Electron. 2016, 31, 5587-5603. [CrossRef]

31. Quesada, J.; Sainz J, A.; Sebastian, R.; Castro, M. Decoupled droop control techniques for inverters in low-voltage AC microgrids. In Proceedings of the 2014 11th International Multi-Conference on Systems, Signals \& Devices (SSD), Barcelona, Spain, 11-14 February 2014; pp. 1-6.

32. He, J.; Li, Y.W.; Munir, M.S. A flexible harmonic control approach through voltage-controlled DG-grid inter-facing converters. IEEE Trans. Industr. Electron. 2012, 59, 444-455. [CrossRef]

33. Programmable DC Power Supply (Solar Array Simulation) Model 62000H-S Series. Available online: http:/ / www.chromausa.com/pdf/62000H-S-E.pdf (accessed on 22 January 2018).

34. Regenerative Grid Simulator Model 61800 Series. Available online: http:/ / www.chromausa.com/pdf/Br61800-Reg-Grid-Sim-122014.pdf (accessed on 22 January 2018).

35. Wang, X.F.; Song, Y.; Irving, M. Modern Power Systems Analysis; Springer: New York, NY, USA, 2008.

36. Yazdani, A.; Iravani, R. Voltage-Sourced Converters in Power Systems: Modeling, Control, and Applications; IEEE Press: Piscataway, NJ, USA; John Wiley: New York, NY, USA, 2010.

(C) 2018 by the authors. Licensee MDPI, Basel, Switzerland. This article is an open access article distributed under the terms and conditions of the Creative Commons Attribution (CC BY) license (http:// creativecommons.org/licenses/by/4.0/). 